\title{
CONTROLLED RELEASE OF DRUGS FROM TABLET COATINGS
}

\author{
Sacide Alsoy Altinkaya \\ Izmir Institute of Technology, Urla-Izmir, Turkey
}

\section{Contents}

6.5.1 Introduction

6.5.2 Tablet Coating Methods

6.5.3 Characterization of Tablet Coatings

6.5.4 Preparation of Asymmetric Membranes

6.5.5 Methods for Optimization of Tablet Coating Formulations

6.5.6 Applications

6.5.6.1 Materials and Methods

6.5.6.2 Results and Discussion

6.5.7 Conclusion

References

Appendix

\subsubsection{INTRODUCTION}

Controlled-release technology for drug delivery applications is designed to target

2 the drug to particular places or cells in the body, to overcome certain tissue and cellular barriers, and to control the duration and level of the drug in the body within a speficied therapeutic window. This usually implies achieving a prolonged, zeroorder release rate over the desired duration of drug delivery. Controlled-release dosage forms provide sustained drug release and require less frequent drug loading than conventional forms. Thus, the toxic side effects of the drug are minimized and

Pharmaceutical Manufacturing Handbook: Production and Processes, edited by Shayne Cox Gad Copyright (C) 2008 John Wiley \& Sons, Inc. 
patient's convenience and compliance are improved. Controlled-release systems are usually classified into four categories based on the rate-limiting step of the release process [1]: (1) diffusion-controlled systems, (2) chemically controlled systems, (3) swelling-controlled systems, and (4) magnetically controlled systems. Diffusioncontrolled systems are formulated in two main geometries: reservoirs and matrices. In matrix systems, the drug is generally uniformly distributed or dissolved throughout a polymer. The release kinetics from these types of systems depend on the quantity and the diffusivity of drug in the matrix and the geometry of the system. The release ra $\equiv$.om matrix systems usually decrease with time due to an increase in the pathlength for diffusion of drug and, thus, their release characteristics are not generally zero order. In the case of chemically controlled systems, the drug is either distributed through a biodegradable polymer or chemically bound to a polymer backbone chain. The drug release from the biodegradable polymer is controlled by degradation of the polymer through penetration of water or a chemical reaction [1]. The drug attached to the polymer is released by hydrolytic or enzymatic cleavage. In swelling-controlled systems, the drug is dissolved or distributed in a glassy polymer matrix. As water penetrates the dry matrix, the polymer swells and its glass transition temperature decreases below the temperature in the matrix. As a result, the glassy-rubbery transition occurs and it allows the release of the drug. The release rate of the drug out of these systems is mainly controlled by the rate and degree of swelling. Alternatively, the drug release can also be controlled magnetically by dispersing the drug and small magnetic beads within a polymer matrix and exposing them to an oscillating external magnetic field. (The drug is released as the matrix is exposed to an oscillating external magnetic field.)

Reservoir systems consist of a drug-containing core surrounded by a polymer membrane. The release rate of drug is controlled by its diffusion through the membrane [1, 2]. In addition to diffusional release, osmotic pumping mechanisms contribute to the total drug release rate if either the drug is highly soluble or an osmotic agent is added to the active core [1-4]. Reservoir systems are prepared in different geometries, such as coated tablets, beads, particles, membrane-based pouches, and microcapsules. The main advantage of these systems is their ability to maintain zero-order release rates $[1,2]$. This is usually achieved by loading the powdered form of drug at a level far above the solubility of drug. Then, the concentration of drug at the internal wall of the reservoir becomes its saturation concentration and zero-order release occurs until the drug is completely dissolved. In addition, drug loading can be higher for these systems compared to other controlled-release systems; thus, the cost of formulation is minimized and the drug is released at a higher rate for a longer period of time. The major disadvantage of the reservoir system is rupture of the rate-controlling membrane if it is subject to dose dumping.

Numerous studies exist in the literature on the drug release from tablet coatings. In the majority of these studies, diffusional drug release takes place from the coatings [5-17]. Various factors such as the type [8, 10, 15], and concentration of the coating material $[7,8,11]$, the type and amount of the plasticizer in the coating solution [10, 12, 15], the thickness of the coating [5], the composition of the tablet core $[6,14]$, the particle size of the coating material $[10,18]$, and the weight gain of the coating $[7, \underline{8}, \underline{11}, \underline{13}, \underline{16]}$ were considered during the formulation of tablet coat- 
ings, and their effects on the drug release rates were investigated. The use of osmotic tablet coating systems are also described in the literature [3, 4, 17, 19-23]. Osmotic systems utilize osmotic pressure difference as a driving force, and in the simplest design they consist of an osmotic core containing drug with and without osmotic agents. Different studies have shown that the release rate of drugs from oral osmotic pump tablet coating systems is governed by various formulation variables such as solubility and osmotic pressure of core components [3, 4, 19-23], number [17] and size of the delivery orifice $[3,4,20,21,23]$, drug loading $[3,4,17]$ thickness of the coating $[3,4,19,21,23]$, composition of the coating solution $[3,4,17,20,21,23]$, and weight of the coating $[17,20,22]$. The coatings prepared in most of these studies have dense structures with or without a hole drilled through the coating through which the drug is delivered. In some cases, drug delivery ports are formed by adding leachable materials to the coating [24,25]. The main problem with these systems, in the absence of a hole, is an excessively prolonged drug release due to the low permeability of the coating. To increase permeability of the coatings, plasticizers and water-soluble additives were incorporated in the coating solution, and multilayer composite coatings $[14,15,24,26,27]$ or multiple-compartment osmotic tablets were prepared $[17,22,28,29]$. The permeability of the tablet coating systems were further improved by changing the structure of the coatings from dense to porous asymmetric ones [30-42]. Asymmetric membrane tablet coatings are characterized by a relatively thin, dense skin layer supported on a highly permeable, thicker, and porous sublayer. The permeabilities and the release rates of the drugs through the asymmetric-membrane capsule/tablet coatings were determined to be higher compared to conventional dense tablet coatings $[30,33,34,39]$. The composition of the coating solution was found to have a significant effect on the structure of these type of coatings and thus on the release rate of the drug [30, 33, 35, 36, 39, 40-42]. In addition, it was reported that the drying condition had a significant impact on the structure of the asymmetric-membrane tablet coating and the release rate of the drug [41]. A review of the literature studies clearly indicates that asymmetric-type tablet coating is a new solution for developing controlled drug delivery systems, since the structure of these types of coatings can be varied easily by changing the preparation conditions without altering the coating material or significantly varying the coating thickness.

This work contains six sections in addition to the introduction. Section 6.5.2-6.5.5 present a brief review of manufacturing methods for the application of coating materials on tablets, characterization methods used to evaluate the uniformity and defects of the tablet coatings, the techniques commonly used for manufacturing asymmetric-type membranes, and modeling approaches employed for optimization of the tablet coating formulations. The aim of the last two sections is to demonstrate the advantages of asymmetric membrane tablet coatings with respect to their drug release properties and the factors that affect the morphology of these types of tablet coatings. To achieve this goal, the in vitro release of a model compound, theophylline, from asymmetric membrane tablet coatings is determined and the morphology of the coatings is examined. In addition, the dynamics of the phase inversion is quantified in terms of ternary-phase diagrams coupled with composition paths determined from a mathematical model developed previously by our group [43]. To draw meaningful and objective conclusions from experimental data and derive 
an empirical expression for the release rate of drug, compositions of the coating solution are chosen using a statistical experimental design.

\subsubsection{TABLET COATING METHODS}

Four basic methods are commonly used for the application of coating materials on drug tablets: (1) pan coating, (2) fluidized-bed coating, (3) compression (press) coating, and (4) melt/dry coating.

Pan Coating The pan coating process is the oldest form of pharmaceutical coating for manufacturing small, coated particles or tablets. In this process, the particles are tumbled in a pan which is rotated at an angle of usually $45^{\circ}$ to the horizontal surface at a speed between 20 and $50 \mathrm{rpm}$ [44]. Coating fluid is sprayed onto the particles from a above by means of an air jet. The hot air blown through the coater evaporates the fluid and dries the film coating. Pan coating is generally preferred to coat large tablets since they are exposed to mechanical damage in other coating operations. The uniformity of the coating applied to the tablets and defects on the coating are important issues from a practical point of view. Operating conditions such as drum speed, drum solids loading, the presence/absence of baffles, air velocity, and temperature influence the movement of tablets within the moving bed, the circulation and surface exposure times spent by a tablet in the bulk of the moving bed and on the surface of the bed, respectively, and the rate of drying, which all in turn determine the uniformity of the coating in a pan coating process [45]. Different experimental tools such as light emission from a single luminous tablet, photographic and manual counting, positron emission particle tracking, magnetic resonance imaging, and near real-time video imaging techniques [45-51] were used to study the motion of tablets in the drum. Simulation of particle movement using discrete-element modeling has also been used to study the movement of tablets [52-55]. In addition, statistical experimental design was utilized to identify the critical processing variables that affect coating uniformity and loading of active agent coated on tablets [56]. Inlet airflow, pan speed, inlet air temperature, coating time, atomization pressure, and fan pressure were investigated as the process variables. Among these variables, atomization pressure, pan speed, and duration of coating were found to be critical process variables with respect to uniformity of the coating.

Fluidized-Bed Coating The basic principle of fluidized-bed coating is to suspend tablets in a moving hot-air stream in the upward direction during the coating process. The coating material is sprayed through a nozzle from the top, the side, or the bottom into the fluidized bed. The solvent in the solution is removed from the coating by the hot-air stream, which also carries the coated tablets/particles. Fluidized-bed coating provides better coating uniformity due to good solid-fluid mixing and minimizes formation of agglomerates. There are various types of fluidized-bed coating equipment, the most commonly used configuration being the Wurster column coater [44], in which a draft tube insert is placed coaxially in the bed to aid the circulation of particles. This column is not suitable for coating of large particles and tablets due to high erosion of solids associated with the higher velocity 
needed to circulate them [57]. Typical operating variables that affect the performance of the fluid bed coating in a Wurster column are airflow rate, air and bed temperature, spray rate, gap height between the draft tube and the air distributor plate, atomizing air pressure, humidity, and solids charge. The product coating uniformity in the Wurster column coating process is primarily determined by the variation in coating per pass and the circulation time distribution. Radioactive particle tracing, magnetic particle tracing, and controlled single- or multiple-pass coating evaluation techniques were commonly used for detecting particle circulation time and distribution $[57,58]$. In addition, several models have been developed to predict the amount of material coated on the particles [59-65].

Compaction Coating In this process, the coating is compressed around a preformed core by using a special tablet press. Compaction coating is especially useful when the drug itself is unstable in the solution and precipitates from the solution in a less stable morphology. On the other hand, the large amount of coating material required limits the applicability of this technology. Another disadvantage of the process is poor adhesion at the coating-core interface which causes physical instability (i.e., friability) [66]. The Press coating process is not useful for coating relatively hard cores which provide essentially no compressibility.

Melt/Dry Coating Film coating processes require water or organic solvent(s). The use of organic solvents causes environmental pollution and excessive cost of recovery while a long time is required to remove the aqueous solvent. Both hot-melt and dry coating techniques eliminate the use of solvents; as a result the processing times become much shorter and the cost of the process is reduced. Melt coating is possible for coating materials that have a low melting temperature and acceptable thermostability. The principal stages in the film formation during dry coating are softening, melting, and curing [67-70]. The process requires larger amount of plasticizer to partially soften and dissolve the polymer.

\subsubsection{CHARACTERIZATION OF TABLET COATINGS}

Tablet coatings are applied to improve tablet swallowability, mask unpleasant tastes and odors, protect the tablet core against water and oxygen, which can degrade the drug in the core, and control the release rate of the drug. The rate of dissolution and bioavailability of a drug are primarily influenced by the quantity and quality of the coating applied on the tablet. Thus, the characterization of the coatings becomes essential in terms of the uniformity and integrity of the coating. A number of instrumental methods ranging from liquid chromatography [71] to various noninvasive spectroscopic probes have been introduced and evaluated as a means of monitoring the coating process. Among these methods, laser-induced breakdown spectroscopy (LIBS) has been used as a rapid technique for assessing the uniformity of the coating thickness [72]; however, the destructive nature of the method has also been reported [73]. Near-infrared spectroscopy has been employed for determining the amount of coating applied [74-76]. The main disadvantage of this method has been identified as imprecision in the calibration and validation models due to uneven distribution of coating from tablet to tablet [77]. Microscopy 
techniques provide direct and accurate measurement of the coating thickness but require laborious sample preparation and are therefore impractical for real-time process monitoring. Recently, Raman spectroscopy combined with multivariate data analysis has been reported as a feasible noninvasive technique to quantify tablet coating thickness and uniformity in the presence of a fluorescent ingredient in the coating formulation [77, 78]. Confocal laser scanning microscopy has been introduced as a novel technique for imaging the film-core interface and surface defects of film-coated tablets [79]. Surface roughness was also determined as an important factor in characterizing the tablet coatings using different imaging and roughness analytical techniques, including optical microscopy, scanning electron microscopy (SEM), laser profilometry, and atomic force microscopy (AFM) [80-84].

\subsubsection{PREPARATION OF ASYMMETRIC MEMBRANES}

Asymmetric membranes are usually produced by phase inversion techniques. In these techniques, an initially homogeneous polymer solution becomes thermodynamically unstable due to different external effects and the phase separates into polymer-lean and polymer-rich phases. The polymer-rich phase forms the matrix of the membrane, while the polymer-lean phase, rich in solvents and nonsolvents, fills the pores. Four main techniques exist to induce phase inversion and thus to prepare asymmetric porous membranes [85]: (a) thermally induced phase separation (TIPS), (b) immersion precipitation (wet casting), (c) vapor-induced phase separation (VIPS), and (d) dry (air) casting.

Thermally Induced Phase Separation In the TIPS process, an initially homogeneous solution consisting of a polymer and solvent(s) phase separates due to a decrease in the solvent quality when the temperature of the casting solution is decreased. After demixing is induced, the solvent is removed by extraction, evaporation, or freeze drying.

Immersion Precipitation (Wet Casting) A homogeneous polymer solution consisting of a polymer and solvent(s) is cast on a support and is immersed in a nonsolvent bath. During the immersion, casting solvent diffuses into the nonsolvent bath and, countercurrently, nonsolvent in the bath penetrates into the solution. The nonsolvent has a limited solubility in the polymer, and when it reaches its critical concentration in the solution, precipitation takes place. Then, the solvent and nonsolvent in the solution are extracted and film is annealed.

Vapor-Induced Phase Separation During the VIPS process, phase separation is induced by penetration of nonsolvent vapor, into the homogeneous polymer solution consisting of polymer and solvent(s). Mass transfer is usually much slower than that in the wet casting process; thus, the VIPS process has been used to obtain membranes with symmetric, cellular, and interconnected pores $\underline{[86,87]}$. 
Dry (Air) Casting In this process, the polymer is dissolved in a mixture of a volatile solvent and a less volatile nonsolvent is cast on a support and exposed to an air stream. During drying of the solution, fast solvent evaporation leads to a decrease in solubility of the polymer, then phase separation takes place.

\subsubsection{METHODS FOR OPTIMIZATION OF TABLET COATING FORMULATIONS}

Tablet coating formulation is composed of various formulation factors and process parameters. The formulation is usually divided into modeling and optimization phases. The modeling phase consists of preparing series of experimental formulations by varying the ingredients and process conditions systematically and measuring their properties. A detailed review of the literature indicates that the response surface method (RSM) has been widely used for modeling and choosing acceptable tablet coating and other pharmaceutical formulations. The RSM includes statistical experimental designs, multiple regression analysis, and optimization algorithms to search the best formulation for a given set of constraints. Full factorial, orthogonal, Box-Behnken, central composite, pseudorandom, and Plackett-Burman designs were used to investigate the effects of tablet core formulation, coating thickness, and process parameters such as mixing time and speed in the pan coating process, inlet airflow, pan speed, inlet air temperature, coating t $\overline{\bar{\nu}}$ atomization pressure, and fan pressure in the fluidized-bed cqating process [88-93]. Artifical neural networks (ANNs) have also been inves $\overline{\overline{\bar{v}}}$ ted as an alternative method for modeling the pharmaceutical formulations [94-106]. In the RSM, the pharmaceutical responses are predicted based on the second-order polynomial equation, which is usually limited to low levels. When a nonlinear relationship between formulation factors and response variables is observed, $\mathrm{t} \equiv \mathrm{\equiv}$ NN approach was shown to give better estimations of optimal formulations [106].

\subsubsection{APPLICATIONS}

Previous sections have reviewed numerous studies in the literature investigating the release mechanisms from the tablet coating systems, their advantages/disadvantages as a control release system, and the methods used to characterize and optimize their formulation. In the following sections, the in vitro performance characteristics of the asymmetric membrane tablet coatings will be illustrated using release studies of a model compound theophylline. For this purpose, first the method used for preparing asymmetric membrane tablet coatings will be explained, then the results of the dissolution studies will be discussed.

\subsubsection{Materials and Methods}

Preparation and Characterization of Tablet Coatings Tablet cores were prepared by compressing the drug without any excipient using a hydraulic press operated at $110 \mathrm{MPa}$. A stainless steel die with a diameter of $1.2 \mathrm{~cm}$ was used to produce 400-mg drug tablet cores. Asymmetric-membrane tablet coatings were applied 
using a dip coating process (Dip Coater Nima, type D1L, serial no. 327). The tablets were dip coated in polymer solutions prepared by dissolving cellulose acetate (Aldrich) in a solution of acetone (Merck) and water. The rate of withdrawal of the tablets from the solution was adjusted to obtain similar final coating thicknesses for each coating formulation. Immediately after coating, tablets were rotated for even distribution of the viscous membrane solution, transferred into an environmental chamber (Angelantoni Industrie, Italy, Challenge series, model number $\mathrm{CH} 250$ ), and kept there for $2 \mathrm{~h}$ to allow for evaporation of both the solvent (acetone) and nonsolvent (water). The temperature and relative humidity of air in the environmental chamber were adjusted to $25^{\circ} \mathrm{C}$ and $50 \%$, respectively. Tablets were allowed to dry further for a minimum of $24 \mathrm{~h}$ at room temperature prior to dissolution experiments. Faster evaporation of acetone and resulting increase in the concentration of water in the coating leads to a decrease in solubility of the cellulose acetate (CA); then phase separation takes place. Consequently, asymmetric-membrane structure forms on the tablet core. Morphology of the coatings was examined using a scanning electron microscope (Philips, XL-30SFEG). Samples were coated with gold palladium using a magnetron sputter coating instrument. The thickness of the dense skin layer, the overall porosity, and the average pore size were determined from image analysis of micrographs showing cross sections of the membranes.

Dissolution Studies The release rate of theophylline from the tablets was determined by the U.S. Pharmacopeia (USP) XXIII dissolution methodology using a dissolution tester (Caleva 10ST). According to this standard, $900 \mathrm{ml}$ of dissolution medium was placed in the vessel and the temperature was maintained constant at $37^{\circ} \mathrm{C}$ using a constant-temperature bath. Then, the tablets were immersed in the vessel and the solution was stirred at a speed of $50 \mathrm{rpm}$. To simulate the actual dissolution environment in the body, the $\mathrm{pH}$ of the dissolution medium was kept at 3 during the first $3.5 \mathrm{~h}$ by adding $8.5 \mathrm{vol} \%$ phosphoric acid to $900 \mathrm{~mL}$ distilled water and then increased to 7.4 by adding $5.3 \mathrm{M} \mathrm{NaOH}$ to the dissolution medium and kept at this value until the end of the experiment. To determine the quantity of drug released from the tablets, samples were taken periodically and assayed by ultraviolet (UV) spectrophotometry (Shimadzu UV-1601) at a wavelength of $272 \mathrm{~nm}$. Dissolution experiments were performed on three tablets and the release profiles were reported as the arithmetic average of the three experimental runs.

Statistical Experimental Design To determine the influence of the cor $\equiv$ ition of the coating solution on the release rate of drug, experiments were stansically designed using a commercial software package called Design-Expert [107]. The system studied in this chapter consists of three components with the following compositional restrictions:

$$
5 \leq \omega_{1} \leq 15 \quad 70 \leq \omega_{2} \leq 90 \quad 5 \leq \omega_{3} \leq 15
$$

where $\omega_{i}$ is the weight percent of component $i$ and 1,2,3 represent CA, acetone, and water, respectively. Any composition outside these limits will probably fail to 
TABLE 1 Theophylline Release Rates from Asymmetric-Membrane Tablet Coatings, Results of Fitting Release Profiles to Zero-Order Kinetics, and Precipitation Times Determined from Model Predictions

\begin{tabular}{lccccc}
\hline \multicolumn{2}{c}{ Compositon $(\mathrm{wt} \%)$} & & & & \\
\cline { 1 - 2 } $\begin{array}{l}\text { Cellulose } \\
\text { Acetate }\end{array}$ & Acetone & Water & $\begin{array}{c}\text { Release Rate } \\
(\mathrm{mg} / \mathrm{min})\end{array}$ & $R^{2}$ & $\begin{array}{c}\text { Precipitation } \\
\text { Time }^{a}(\mathrm{~s})\end{array}$ \\
\hline 15 & 80 & 5 & 0.036 & 0.9871 & $2671 / 2671$ \\
15 & 80 & 5 & 0.036 & 0.9864 & $2671 / 2671$ \\
5 & 90 & 5 & 0.45 & 0.9757 & $660 / 660$ \\
5 & 90 & 5 & 0.36 & 0.9864 & $660 / 660$ \\
15 & 70 & 15 & 0.036 & 0.9908 & $3374 / 3374$ \\
15 & 70 & 15 & 0.027 & 0.9925 & $3374 / 3374$ \\
5 & 80 & 15 & 0.36 & 0.9928 & $1000 / 1000$ \\
5 & 80 & 15 & 0.36 & 0.9876 & $1000 / 1000$ \\
5 & 85 & 10 & 0.27 & 0.9918 & $675 / 675$ \\
10 & 80 & 10 & 0.054 & 0.9958 & $1751 / 1751$ \\
15 & 75 & 10 & 0.054 & 0.9975 & $2314 / 2314$ \\
10 & 85 & 5 & 0.036 & 0.9887 & $2554 / 2554$ \\
12.5 & 77.5 & 10 & 0.036 & 0.9902 & - \\
10 & 75 & 15 & 0.063 & 0.9889 & $1484 / 1484$ \\
\hline
\end{tabular}

${ }^{a}$ The first number corresponds to the precipitation time at the tablet-coating interface.

produce a successful asymmetric-membrane coating. In mixture experiments, the factors are the compositions of the mixture components, and the sum of the fractions of all components is equal to 1 . Therefore the factor levels are mutually dependent. Thus, factorial experimental designs are not suitable for response surface modeling of mixtures since such designs require that the experimental treatment combinations be determined by independent adjustments of each component level. In addition, a standard response surface design cannot be used either due to the same constraints. Consequently using the constraint levels shown in Equation (1), a $D$ optimal design was generated by the Design-Expert software package. The 14 experimental formulations determined are shown in Table 1. The lower and upper limits on the weight fraction of each component are required to (a) obtain appropriate viscosity of the solution and coat the tablets uniformly and (b) induce phase separation, thus forming a porous membrane structure. These constraints were established based on preliminary dissolution experiments, available literature data, and the simulation results reported by Altinkaya and Ozbas [43].

Of the 14 formulations listed in Table 1, six experimental runs were required to fit the quadratic mixture model, four additional distinct runs were used to check for the lack of fit, and finally four runs were replicated to provide an estimate of pure error. Design-Expert used the vertices, the edge centers, the overall centroid, and one point locajed halfway between the overall centroid and one of the edge centers as candidate $p$ s. Additionally, four vertices of the design region were used as check points [107].

Determination of Phase Diagrams and Composition Paths The dynamics of the membrane formation process is predicted by combining the kinetics and thermody- 
namics of the system simultaneously. An appropriate thermodynamic model is necessary to construct the ternary-phase diagram and to formulate the boundary conditions of the kinetic model. Phase separation is considered to occur when a mass transfer path touches the binodal curve. In this study, a robust algorithm developed previously by our group was used to construct the phase diagram [43]. The algorithm utilizes Flory Huggins thermodynamic theory with constant interaction parameters. The composition paths were determined from the kinetic model equations which consist of coupled unsteady-state heat and mass transfer equations, film shrinkage, and complex boundary conditions. The details of both the thermodynamics and kinetic equations can be found in our previous study [43]. We have assumed that the kinetic model derived for a plane geometry can be used to predict the membrane formation process on a tablet surface. This assumption is fairly reasonable since the thickness of the coating is very small and, thus, the cylindrical geometry can be approximated as the plane geometry.

\subsubsection{Results and Discussion}

Effect of Composition of Copting Solution The effect of changing the composition of the casting solution is $n$ for separation applications [108-115]. However, there are relatively few quantitative studies illustrating the relationship between the composition of the casting solution and the drug release rate from the asymmetric-membrane coated tablets/capsules $[30,33]$. To investigate such a relationship, the in vitro release profiles of the model drug theophylline were measured for the 14 formulations listed in Table 1 and they are shown in the Appendix in Figures A1-A10. To find out whether the drug release from the tablet coatings provides a zero-order release kinetics, each data set was fitted to a linear equation. The quality of the fitted model is determined by the coefficient of determination $R^{2}$ and it is defined as

$$
R^{2}=\frac{\sigma_{y}-\hat{\sigma}_{y}}{\sigma_{y}}
$$

where

$$
\begin{gathered}
\sigma_{y}=\frac{1}{n} \sum_{i=1}^{n}\left(Y_{i}-\bar{Y}\right)^{2} \\
\hat{\sigma}_{y}=\frac{1}{n} \sum_{i=1}^{n}\left(Y_{i}-\hat{Y}_{i}\right)^{2}
\end{gathered}
$$

denote the sample variance and the prediction error power, respectively. Additionally, $n$ is the number of experimental data points, $Y_{i}$ is the experimental observation, $\bar{Y}$ is the average of the experimental data points, and $\hat{Y}_{i}$ denotes the predicted value by the fitted model. The quantity $R^{2}$ lies between 0 and 1 , and if the value is 1 , it can be said that the fit of the model is perfect. High $R^{2}$ values listed in Table 1 for each data set indicate that there is an excellent linear relationship between the concentration of the drug and the release time; thus, all tablet coatings prepared 


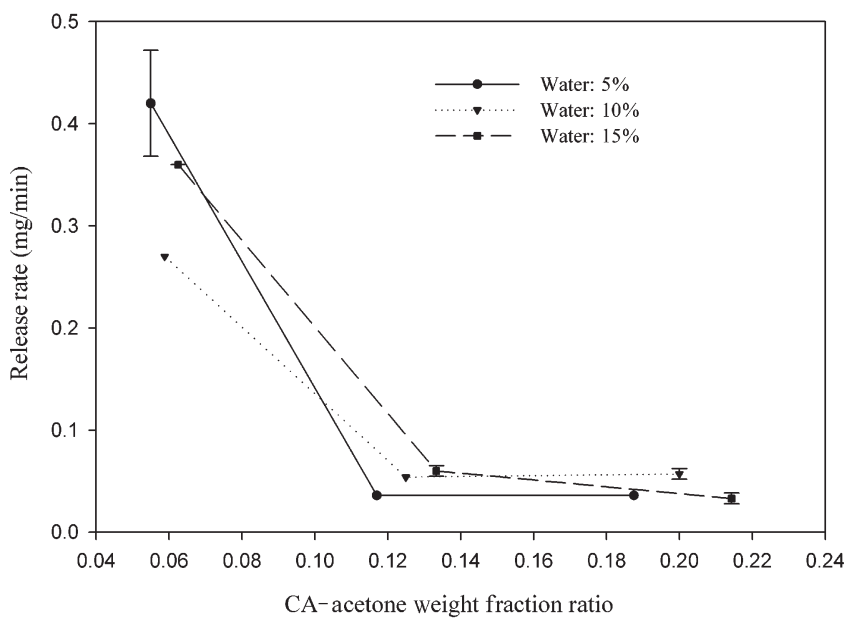

FIGURE 1 Release rate of theophylline as function of cellulose acetate(P)-acetone(S) weight fraction ratios.

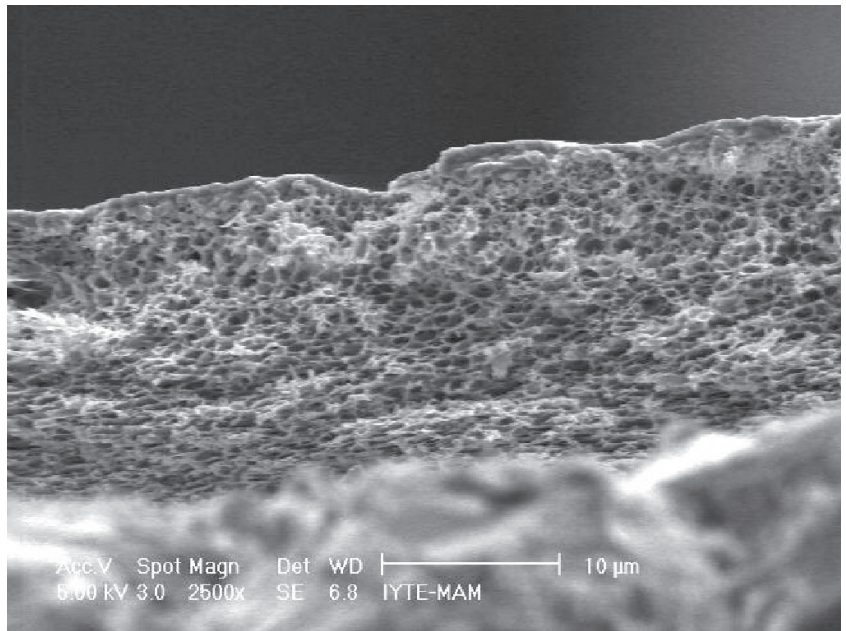

FIGURE 2 SEM of cross section of asymmetric-membrane made with 5\% water and CA-acetone weight ratio of 5/90, magnification $2500 \times$.

can provide zero-order or near-zero-order drug release. The release rates for each coating formulation were estimated from the slope of the average release profiles and they are also listed in Table 1.

The drastic change in the release rates with the composition of the coating solution is shown in Figure 1. Within the experimental composition range covered, the highest release rate was observed in the case of the lowest CA (P: polymer) and the highest acetone ( $\mathrm{S}$ : solvent) concentrations in the casting solution [polymer (P)solvent (S) weight fraction ratio 5/90]. This is caused by the final coating structure consisting of a very thin and dense top skin layer, and highly porous lower sublayer, as illustrated in Figure 2. At the lowest level of polymer concentration $(5 \%)$, the 
thicknesses of the dense skin layers of the coatings are very small and similar to each other; thus, the structure of the lower sublayer becomes an important factor in determining the release rate of the drug. The porosity of the coating structure in the case of $90 \%$ acetone is so high that an increase in water concentration from 5 to $10 \%$ is not sufficient to produce a more porous final structure and, thus, the release rate of the drug decreases. A further increase of water concentration to $15 \%$ results in an opposite effect, which makes the release rate increase to a level of $0.36 \mathrm{mg} / \mathrm{min}$ due to the dominant effect of water concentration in increasing the porosity of the lower sublayer.

An increment in the CA concentration from 5 to $10 \%$ resulted in significantly lower release rates at all water concentrations because the structure of the coatings changed from porous to dense. Keeping the polymer concentration at $10 \%$ while changing the water concentration from 5 to $15 \%$ makes the release rates increase. This behavior is explained by the formation of more porous structures by adding more nonsolvent into the casting solution, which is in agreement with the observations of other groups [30, 33].

When the polymer concentration increases from 10 to $15 \%$, no significant changes in release rates were observed. As a matter of fact, in the cases of $5 \%$ and $10 \%$ water concentrations, the release rates did not change at all. This is due to the unusual transport characteristics of asymmetric membranes which are complex functions of the properties of the different regions of the membrane. In addition to the thickness of the dense skin layer and the porosity of the lower sublayer, structural factors such as tortuosity, pore size, shape, and connectivity of the pores also strongly affect the rate of transport through the coating. The SEM pictures taken at high magnification which are shown in Figures $3 a$ and $3 b$ indicate that the tablet coating prepared with a $\mathrm{P} / \mathrm{S}$ ratio of $10 / 85$ has a uniform and narrow pore size distribution with regular elliptic pore shapes, while the other one (P/S: 15/80) has cylindrical pores with a wide pore size distribution, forming a connected pore network. As a result, even though the resistance of the dense skin layer of the coating made with $\mathrm{P} / \mathrm{S}$ ratio of $15 / 80$ is larger, its lower sublayer resistance is smaller due to the connected pore network. Consequently, the release rate of the theophylline becomes the same through both tablet coatings. Comparison of the scanning electron micrographs in Figures $4 a$ and $4 b$ indicates that the tablet coating made with the $\mathrm{P} / \mathrm{S}$ ratio of $10 / 80$ has a uniform pore size distribution, cylindrical pore shapes and high tortuosity while the tablet coating prepared with the P/S ratio of $15 / 75$ has elliptic, irregular pore shapes and pores are isolated. Thus, the lower sublayer resistance of the coating made with the $\mathrm{P} / \mathrm{S}$ ratio of $10 / 80$ is larger due to the relatively higher tortuosity resulting in the same release rate with the coating prepared with the $\mathrm{P} / \mathrm{S}$ ratio of $15 / 75$.

At the $15 \%$ polymer concentration level, the release rate increases with the change in water concentration from 5 to $10 \%$, which is mainly caused by the increased porosity. However, a further $5 \%$ increment in the water concentration (to $15 \%$ ) made the release rate decrease back to the same level as in the case of $5 \%$ water concentration. Even though higher water concentration favors forming a more porous structure and a concomitant higher release rate, the acetone level which decreased below a critical value destroyed this mechanism. 


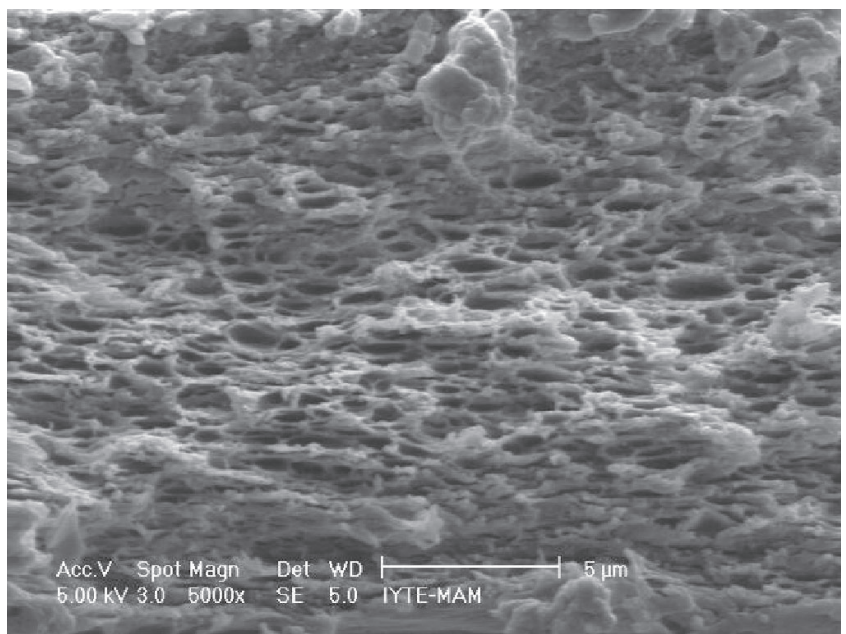

(a)

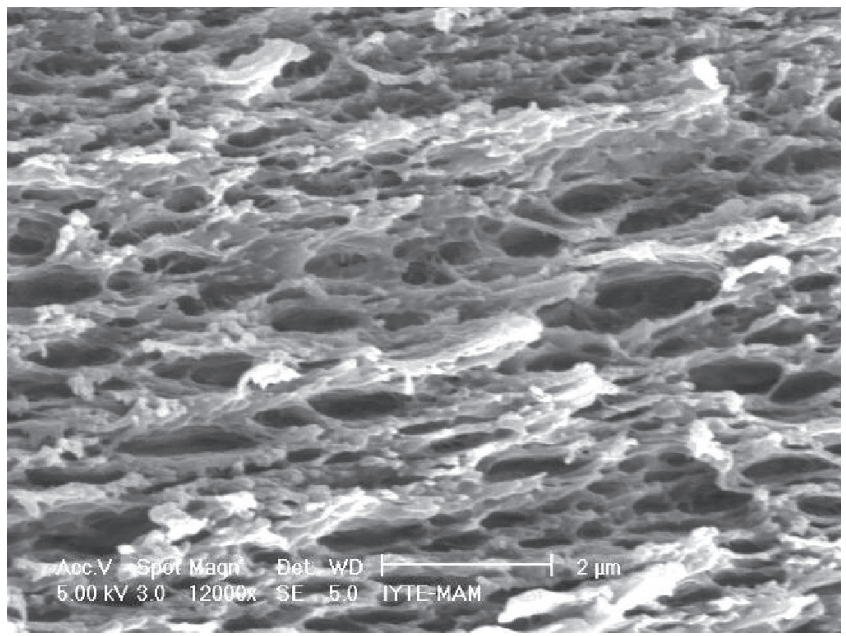

(b)

FIGURE 3 SEM of cross section of asymmetric-membrane made with $5 \%$ water and CA/acetone weight ratios of: (a) 10/85, magnification 5000× (b) 15/80, magnification $12,000 \times$.

Results of dissolution studies along with morphological observations clearly indicate that the drug release rate is strongly influenced by the morphology of the membrane. Thus, if one wishes to control the drug release characteristics of the delivery system, a quantitative understanding of the dynamics and morphology of the phase inversion process is required. The dynamics of the phase inversion process can be quantified in terms of the ternary-phase diagram coupled with the heat and mass transfer model equations. We have obtained information about the structure of the tablet coating by plotting the composition paths on the ternary-phase diagram and the polymer concentration profile at the moment of precipitation. As an illustra- 


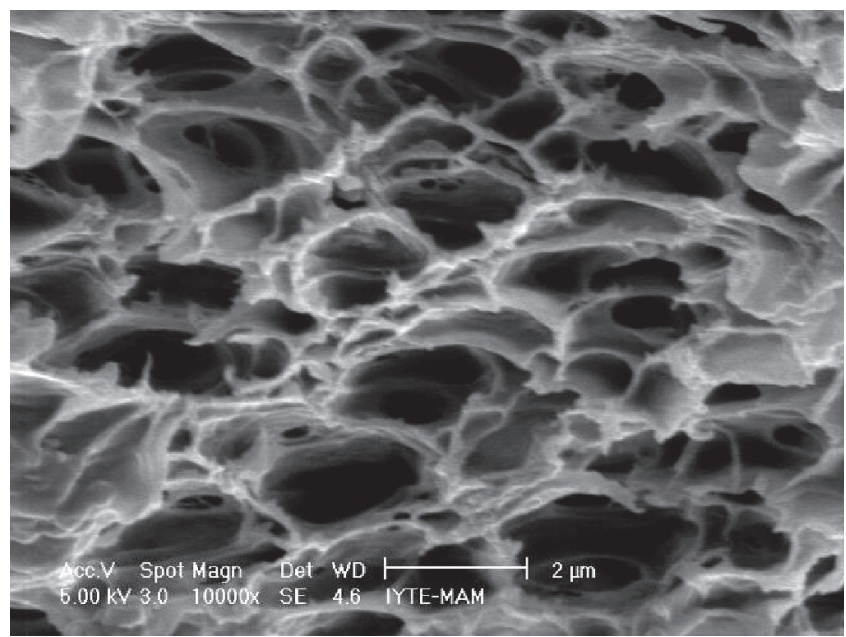

(a)

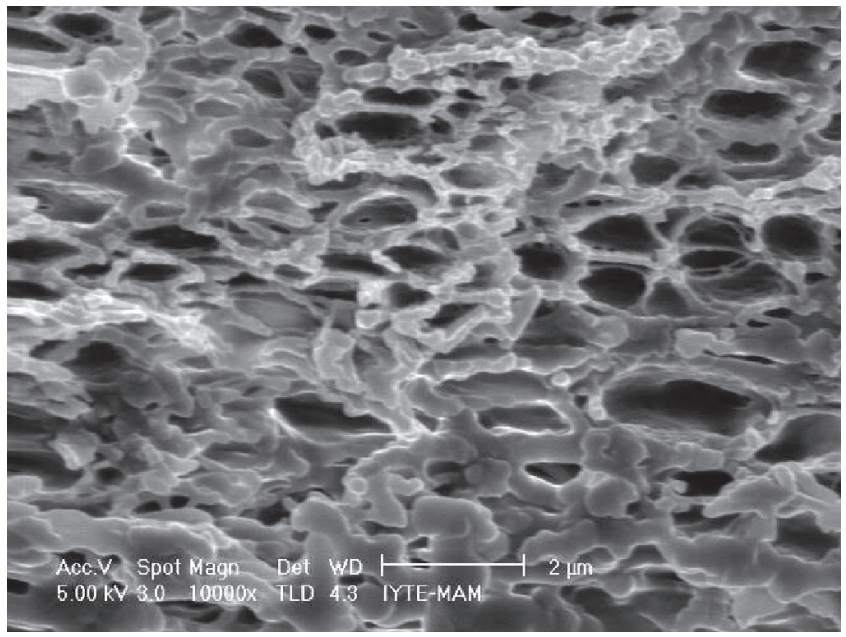

(b)

FIGURE 4 SEM of the cross section of the asymmetric-membrane made with $10 \%$ water and CA-acetone weight ratios of (a) 10/80, magnification 10,000×, and (b) 15/75, magnification $10,000 \times$.

tion, in Figure 5, concentration paths in time for the tablet coating prepared with $5 \%$ CA, $90 \%$ acetone, and 5\% water are shown. According to this plot, the phase separation takes place since the concentration paths in time for the drug tabletcoating and the coating-air interface cross the binodal curve at the same time. In addition, the coating-air interface enters the phase envelope at a polymer volume fraction of 0.76 , while the tablet-coating interface enters with a volume fraction of 5 0.023. These two observations imply that the coating will be porous and asymmetric in which the top layer is more dense than the lower sublayer, which was confirmed by the SEM picture in Figure 2. The predictions, have shown that phase separation was achieved for all coating formulations, supporting the morphological observa- 


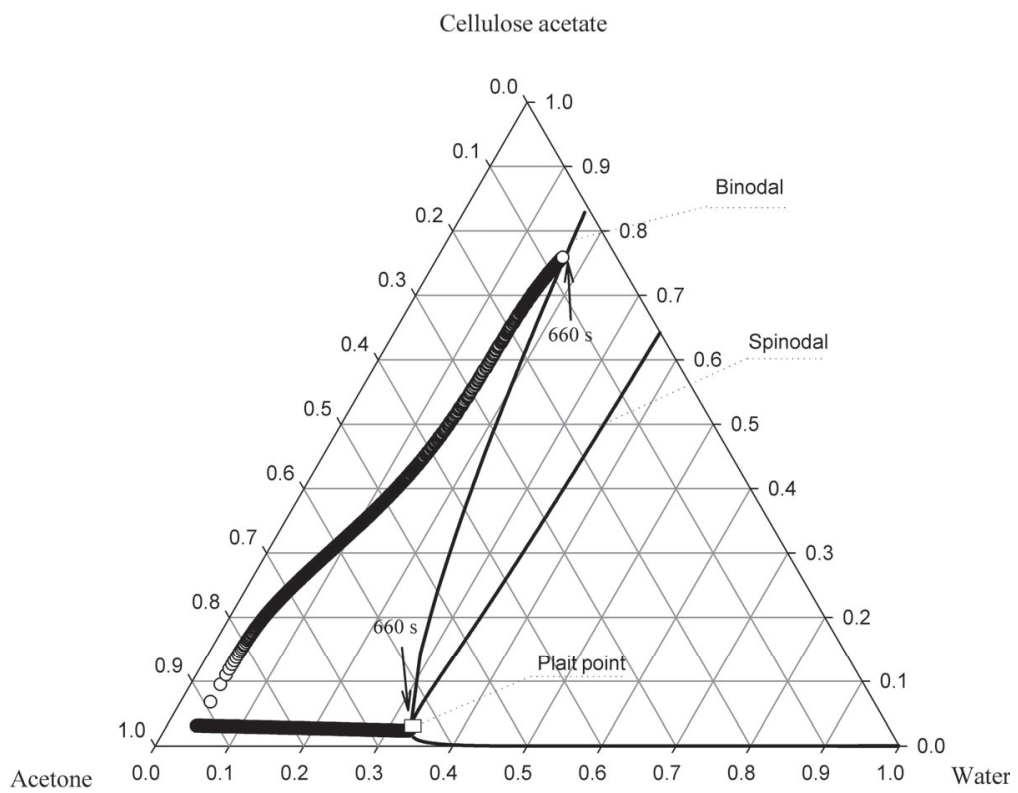

FIGURE 5 Ternary-phase diagram and concentration paths for coating made with 5\% CA dissolved in $90 \%$ acetone and $5 \%$ water.

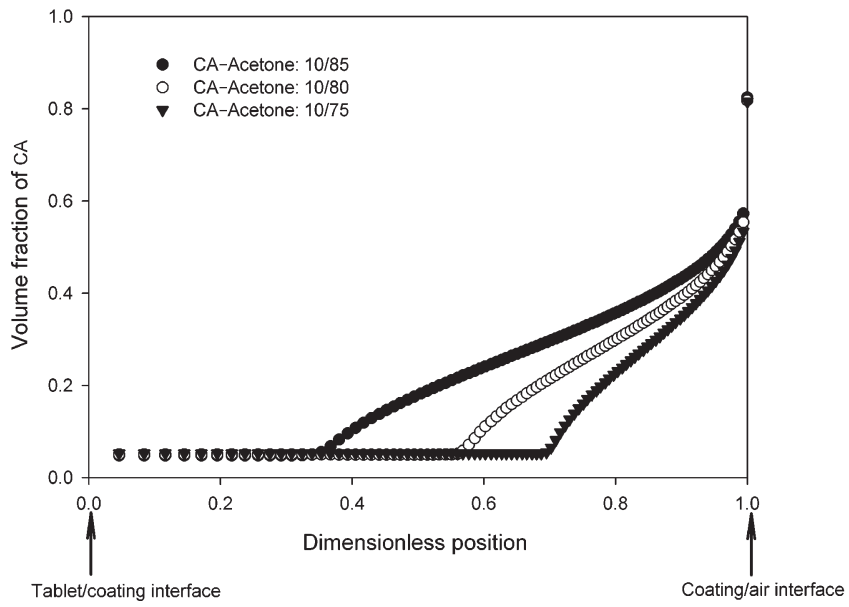

FIGURE 6 Concentration profile of CA in membrane at moment of precipitation for different $\mathrm{CA}$-acetone weight fraction ratios.

tions and the precipitation times calculated for each case (listed in Table 1). Model predictions can also be used to determine a rough thickness of the high-polymerconcentration region near the coating-air interface and the pore distribution of the sublayer structure when the polymer concentration profiles at the moment of phase separation are plotted. As an illustration, such a plot is shown in Figure 6 for coatings prepared with $10 \% \mathrm{CA}$ in the casting solution. Examination of these profiles 
leads to the following conclusions regarding the effect of increased water concentration: (1) The polymer concentration at the coating-air interface slightly decreases. (2) More uniform porosity distribution throughout the lower sublayer is favored. Also, porosity increases, which is in complete agreement with our release studies and the observations of other groups [30, 33].

Effect of Evaporation Condition Previous studies on more traditional applications have investigated the effect of increased air velocity, that is, forced-convectin conditions for a combination of dry/wet phase inversion techniques to prod市 defect-free, ultrahigh flux asymmetric membranes with ultrathin skin layers [116118]. To investigate the effect of evaporation condition on the release rate of drug, tablets were dip coated with CA solution containing 10\% CA, $80 \%$ acetone, and $10 \%$ water and allowed to dry by blowing air across the surface with a blower (forced convection). As a comparison, tablets coated with the same solution were air dried under natural free-convection conditions.

As illustrated in Figure 7, the release profiles of both tablet coatings show a linear behavior only at small times, and then exponential increases in concentrations were observed. Based on this behavior, the release profiles were fitted to an empirical equation as

$$
C=k_{0} t\left\lfloor 1+e^{b_{0} C t}\right\rfloor
$$

where $k_{0}$ and $b_{0}$ are fitting parameters. The accuracy of Equation (5) for correlating the release rate data in Figure 7 was confirmed by high $R^{2}$ values, very close to 1 in both cases. Due to the presence of the second term in Equation (5), the release rate

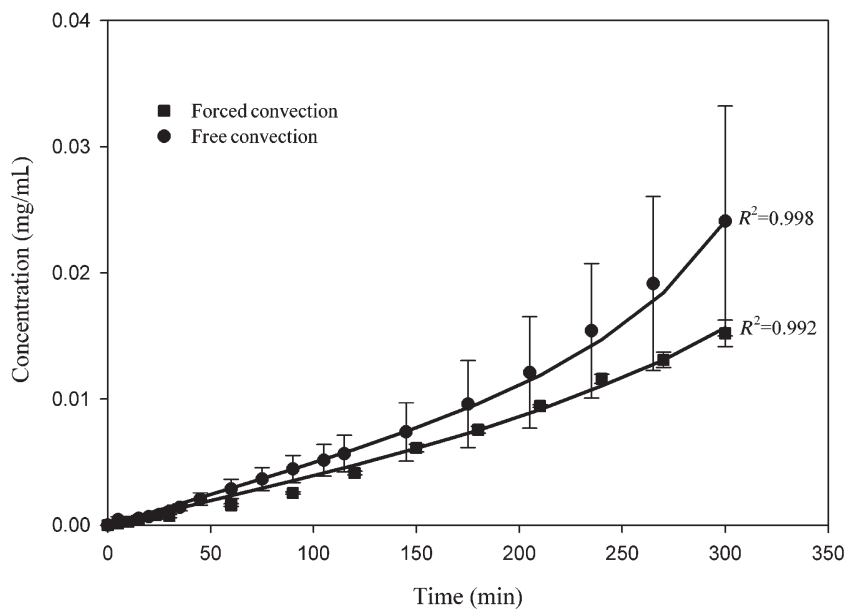

FIGURE 7 Release of theophylline from tablet coatings made with 10\% CA dissolved in $80 \%$ acetone and $10 \%$ water. Coated tablets were dried under free- and forced-convection conditions. The lines correspond to prediction from Equation (5) using $k_{0}=1.92 \times$ $10^{-5} \mathrm{mg} /(\mathrm{mL} \cdot \mathrm{min}) ; b_{0}=0.1179 \mathrm{~mL} /(\mathrm{mg} \cdot \mathrm{min})$ for forced convection and $k_{0}=2.41 \times$ $10^{-5} \mathrm{mg} /(\mathrm{mL} \cdot \mathrm{min}) ; b_{0}=0.1174 \mathrm{~mL} /(\mathrm{mg} \cdot \mathrm{min})$ for free convection. 
of the drug, $d C / d t$, is no longer constant and its dependency on the concentration of drug in the dissolution medium, $C$, can be expressed as

$$
\frac{d C}{d t}=\frac{k_{0}\left\lfloor 1+e^{b_{0} C t}\left(1+b_{0} C t\right)\right\rfloor}{1-k_{0} b_{0} t^{2} e^{b_{0} C t}}
$$

Using Equation (6), the release rate of theophylline from the tablets dried under forced- and free-convection conditions were determined as 0.047 and $0.078 \mathrm{mg} / \mathrm{min}$, respectively. It shoud be noted that both of these values correspond to the arithmetic average of the release rates calculated at each average concentration level shown in Figure 7. The difference in release rates can be explained by comparing the scanning electron micrographs shown in Figures $8 a$ and $8 b$. It can be seen that the crosssectional morphology of the tablet coating dried under the forced-convection condition is dense and nonporous while a porous and asymmetric structure is observed for the tablet coating dried under free-convection conditions. In the dense coating, diffusional resistance to transport of the drug occurs through the overall thickness and is larger than that in the asymmetric porous coating; hence, a lower drug release rate is observed. To understand the effect of air velocity on the formation of the coating structure, we have utilized our model predictions. The composition paths plotted in Figure 9 indicate that, when the speed of air in the drying atmosphere is significantly increased, the rate of evaporation of solvent (acetone) increases dramatically and within a short time its concentration at the surface drops to zero. This situation leads to very strong diffusional resistance within the membrane solution and, thus, slow evaporation of the nonsolvent (water). Consequently, phase separation is never achieved and the resulting membrane structure becomes dense as supported by the SEM picture in Figure $8 a$.

Effect of Nonsolvent Ty $\equiv$ A few studies in the literature have shown that various membrane morphologiesean be obtained by changing the type of nonsolvent in the casting solution [119-121]. To investigate the effect of nonsolvent type, tablet coatings were prepared from a casting solution of CA in acetone as a solvent and octanol, formamide, glycerol, and hexanol as nonsolvents. The drastic change in the release rates of theophylline and percentage of dense skin layer at the surface of the tablet coating with nonsolvent type is shown in Figure 10. The decrease in the release rates is associated with the increase in the thickness of dense skin layer of the coating. The results illustrated in Figure 10 indicate that the membrane structure formation during the phase inversion process is strongly influenced by the type of nonsolvent, since each nonsolvent has different volatility, thermodynamic, and diffusion characteristics. The difference in the rates of evaporation and diffusion of nonsolvents and change in the miscibility gaps in the case of each nonsolvent lead to different mass transfer paths; consequently, the morphology of the resulting membrane structures significantly varies from porous symmetric to dense asymmetric ones.

Statistical Analysis of Experimental Design The effect of the composition of the coating solution on the release rate of drug was investigated in detail with the 14 formulations listed in Table 1. The drug release rate was chosen as an appropriate 


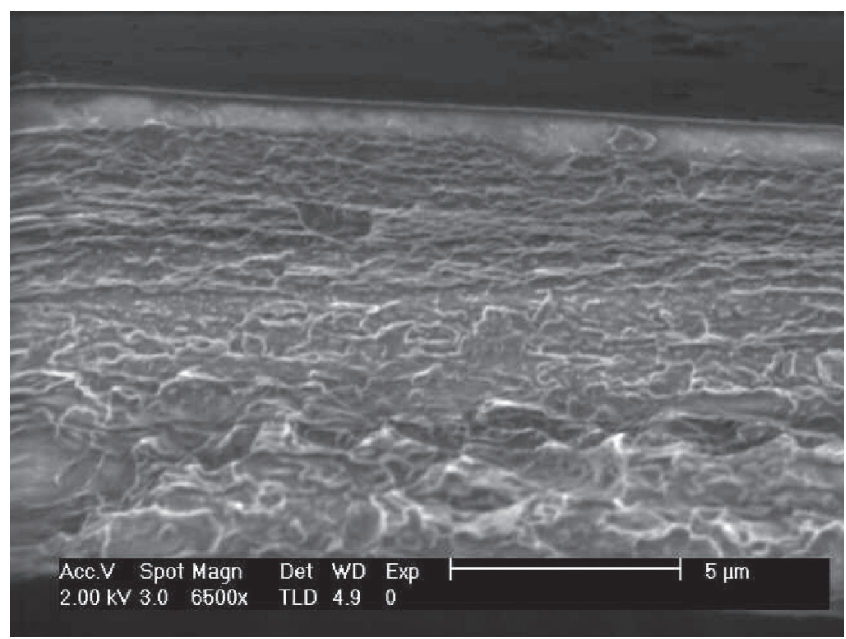

(a)

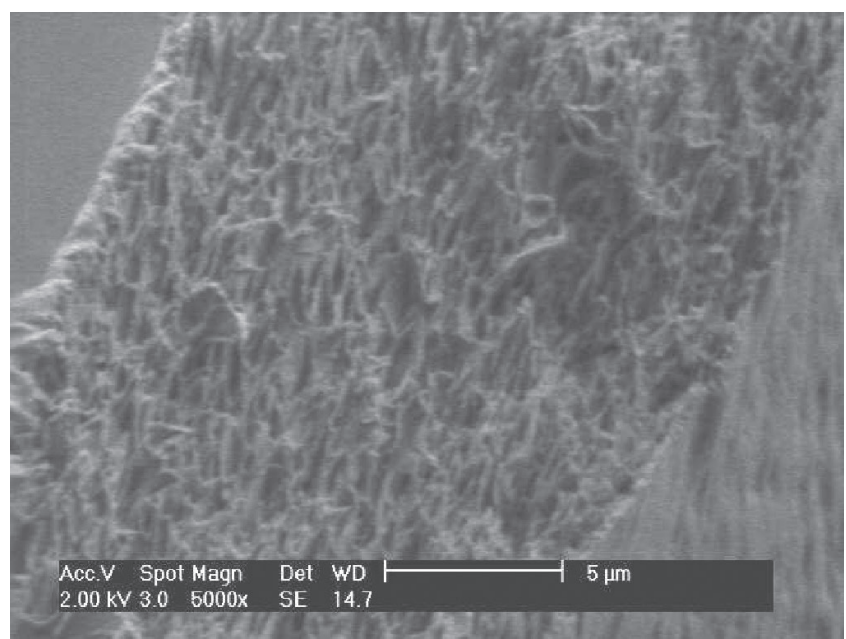

(b)

FIGURE 8 SEM of cross section of asymmetric-membrane made with 10\% CA dissolved in $80 \%$ acetone and $10 \%$ water: $(a)$ coating solution was dried under forced-convection condition, magnification 6500×; $(b)$ coating solution was dried under free-convection condition, magnification $5000 \times$.

response variable since zero-order release was easily achieved for all tablet coatings prepared. The data in Table 1 were best fit by the special cubic equation

$$
\begin{aligned}
\text { Release rate }= & 70.94 \omega_{1}+1.698 \omega_{2}+37.55 \omega_{3}-94.66 \omega_{1} \omega_{2} \\
& -354.3 \omega_{1} \omega_{3}-49.3 \omega_{2} \omega_{3}+357.66 \omega_{1} \omega_{1} \omega_{3}
\end{aligned}
$$

Results of the regression analysis are given in Table 2. An excellent fit of the experimental release rate data to Equation (7) was confirmed by the high $R^{2}$ value of 0.9801 . In addition to the $R^{2}$ values, the significance of Equation (7) and each 


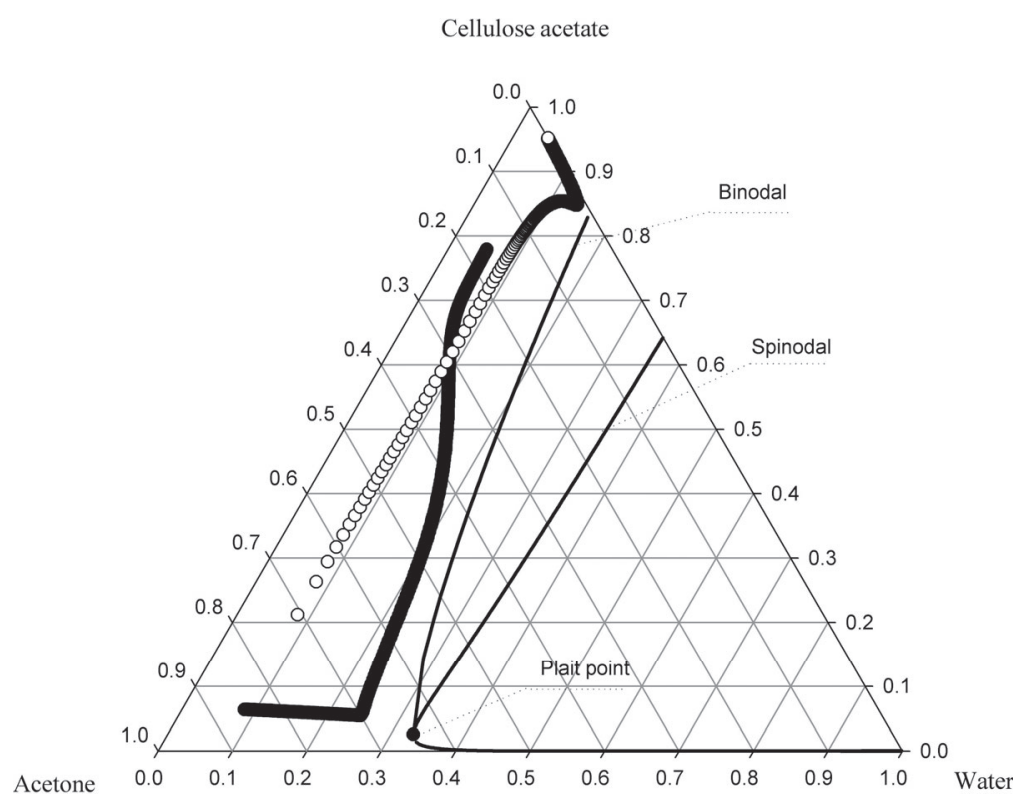

FIGURE 9 Ternary-phase diagram and concentration paths for coating made with $10 \%$ CA dissolved in $80 \%$ acetone and $10 \%$ water. Coating solution was dried under forced-convection condition.

\section{Release rate $\square$ Skin}

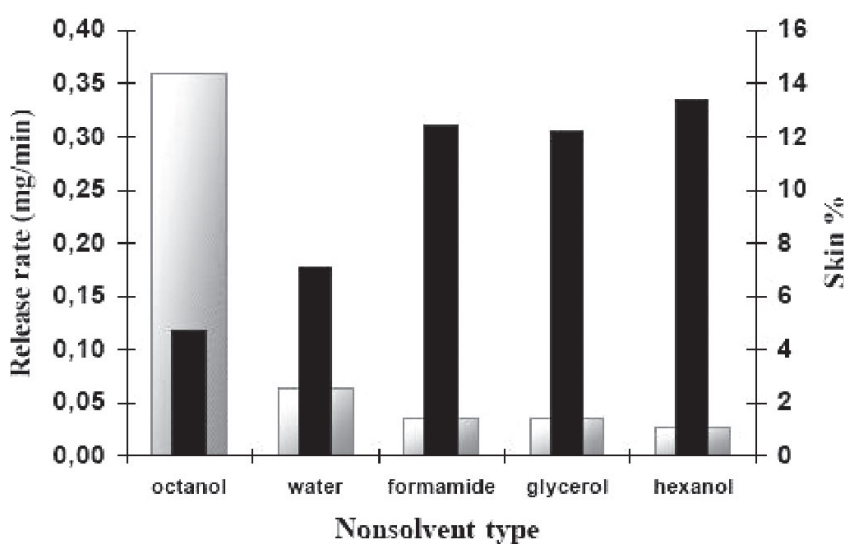

FIGURE 10 Release rates of theophylline and percentage of dense skin layer of membranes as function of nonsolvent type. Polymer: CA solvent-acetone.

term in it to the prediction of the release rate of theophylline was evaluated by the $F$ statistic or $F$ value. The $F$ statistic is viewed as a ratio that expresses variance explained by the model divided by variance due to model error or experimental error and is defined as

$$
F=\frac{R^{2} / k}{\left(1-R^{2}\right) /(n-k-1)}
$$


TABLE 2 Statistical Analysis of Release Rate Data

\begin{tabular}{|c|c|c|c|c|c|c|}
\hline \multirow[b]{2}{*}{ Model Number } & \multirow[b]{2}{*}{$R^{2}$} & \multirow[b]{2}{*}{$F$ values } & \multicolumn{2}{|c|}{$\alpha=0.05$} & \multicolumn{2}{|c|}{$\alpha=0.01$} \\
\hline & & & $F_{\text {critic }^{a}}{ }^{a}$ & $\Delta F$ & $F_{\text {critic }^{a}}{ }^{a}$ & $\Delta F$ \\
\hline 1 (full model) & 0.9801 & 42.21 & 4.21 & 38 & 8.26 & 33.95 \\
\hline $2\left(\omega_{1} \omega_{2} \omega_{3}\right)$ & 0.955 & 25.13 & 3.87 & 21.26 & 7.19 & 17.94 \\
\hline $3\left(\omega_{2} \omega_{3}\right)$ & 0.953 & 23.57 & 3.87 & 19.7 & 7.19 & 16.38 \\
\hline $4\left(\omega_{1} \omega_{3}\right)$ & 0.946 & 20.64 & 3.87 & 16.77 & 7.19 & 13.45 \\
\hline $5\left(\omega_{1} \omega_{2}\right)$ & 0.881 & $\bar{\equiv} .65$ & 3.87 & 4.78 & 7.19 & 1.46 \\
\hline
\end{tabular}

${ }^{a}$ Determined from statistical tables [122].

where $k$ is the number of variables in the model. Usually the computed value of $F$ is compared with the critical $F$ value, $F_{k, n-k, 1-\alpha}$, where $\alpha$ is a preselected significance level. If the value of $F$ is substantially greater than the critical $F$ value $\left(F_{\text {critic }}\right)$, that is, if $\Delta F$, the difference between $F$ and $F_{\text {critic }}$, is large, then the regression equation is considered useful in predicting the response. We have assessed the contribution of each interaction term by comparing the change in $\Delta F$ and $R^{2}$ values between the full model given in Equation (7) and reduced models. The reduced models were obtained by deleting a specific interaction term in the full model; for example, model 2 includes all terms in Equation (7) except the term involving $\omega_{1} \omega_{2} \omega_{3}$. The results in Table 2 indicate that all binary and ternary interaction terms in the full model are needed for accurate prediction of the release rate since the largest $\Delta F$ values are calculated for the full model for both significance levels, $\alpha=0.05$ and $\alpha=0.01$. According to the criterion mentioned above, among all interactions, CA-acetone $\left(\omega_{1} \omega_{2}\right)$ was identified as the most influential factor on the response since the largest decrease in both $\Delta F$ and $R^{2}$ values compared to those of the full model were observed when the term $\omega_{1} \omega_{2}$ was deleted from the full model. This simply implies that changing the $\mathrm{CA}$-acetone ratio in the coating formulation has the most significant effect on the release rate. Specifically, increasing the ratio of CA to acetone from $5 / 90$ to $15 / 80$ resulted in a decrease of the release rate from 0.45 to $0.036 \mathrm{mg} /$ min since the porosity of the membrane decreases and the thickness of the dense skin layer increases. The ratio of the composition of CA to water $\left(\omega_{1} \omega_{3}\right)$ was also found to be an important parameter on the release rate of drug as indicated by the second largest decrease in $R^{2}$ and $\Delta F$ values compared to those of the full model. Decreasing this ratio from $15 / 5$ to $5 / 15$ caused an increase in the release rate by a factor of 10 since the thickness of the dense skin layer significantly decreases. Based on the decrease in $\Delta F$ and $R^{2}$ values from those of the full model given in Table 2, the relative importance of each interaction term can be ranked as follows: $\omega_{1} \omega_{2}>$ $\omega_{1} \omega_{3}>\omega_{2} \omega_{3}>\omega_{1} \omega_{2} \omega_{3}$.

To further illustrate the simultaneous effects of the factors on the release rate of drug, a three-dimensional response surface plot based on Equation (7) was generated, as shown in Figure 11. As can be clearly seen from this figure, the release rate can be significantly varied just by tailoring the $\mathrm{CA}$-acetone and $\mathrm{CA}$-water ratios without changing the coating material. In addition, Figure 11 shows that a slight maximum in release rate is observed as the ratio of composition of acetone to water increases.

In order to validate the predictive capability of the empirical expression, two formulations with compositions given in Table 3 were selected randomly from the 


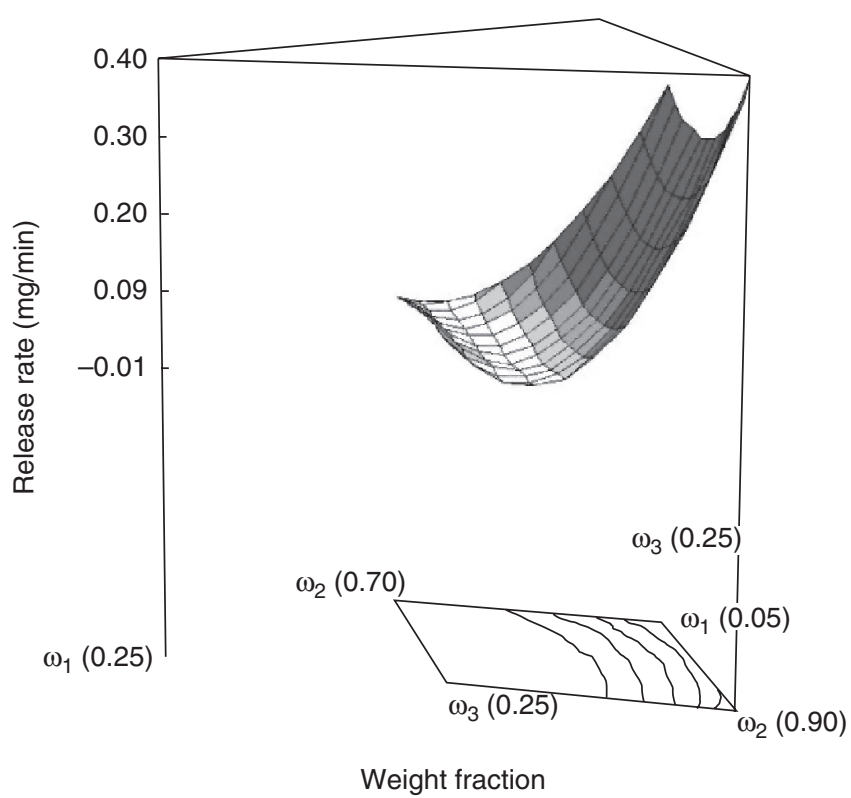

FIGURE 11 Three-dimensional response surface plot of release rate as function of composition of coating solution.

TABLE 3 Composition of Coating Solution Randomly Selected for Testing Predictive Capability of Empirical Expression

\begin{tabular}{lccccr}
\hline \multicolumn{2}{c}{ Compositon $(\mathrm{wt} \%)$} & & $\begin{array}{c}\text { Experimental } \\
\text { Release Rate } \\
(\mathrm{mg} / \mathrm{min})\end{array}$ & $\begin{array}{c}\text { Predicted } \\
\text { Release Rate } \\
(\mathrm{mg} / \mathrm{min})\end{array}$ & $R^{2}$ \\
$\begin{array}{lcccc}\text { Acetlulose } \\
7.5\end{array}$ & Acetone & Water & 0.09 & 0.125 & 0.9816 \\
10 & 82.5 & 10 & 0.027 & 0.029 & 0.9858 \\
\hline
\end{tabular}

experimental design region. Experimental release rates estimated from the slope of the release profiles and corresponding rates predicted from Equation (7) are also listed in Table 3. According to the results, the maximum absolute percentage difference between the experimental and predicted release rates is $3.5 \%$. This value lies within the residuals obtained in deriving Equation (7). Based on this comparison, it is fair to conclude that the empirical expression derived in this study can be used as a tool to predict the release rate of theophylline for any composition within the experimental design region.

\subsubsection{CONCLUSION}

This chapter has considered the controlled release of drugs from tablet coating systems. These systems are still the preferred route of drug administration due to 
their advantages of ease of administration, maintaining zero-order release rates, and better patient compliance; thus, they hold the major market share in the pharmaceutical industry along with the other formulations of oral drug delivery. In tablet coated systems, diffusion of drug through the coating is usually the rate-limiting step and the desired drug release rates are achieved by properly selecting the coating material and adjusting the morphology of the coating using suitable manufacturing methods. Coating characteristics such as glass transition temperature, crystalline content, and degree of cross-linking significantly determine the release rate of the drug. For a selected coating material, the structure of the coating plays a critical role in achieving useful release rates. The morpholology of the tablet coatings can be varied by incorporating plasticizer or water-soluble additives in the coating solution, by blending the polymers, or by applying multilayer composite coatings. Another approach is to apply asymmetric- and porous-type coatings. The morphological characteristics of these types of coatings, such as fraction of dense top layer and porous sublayer and size and shape of the pores, can be varied by optimizing the composition of the coating solution, evaporation conditions (temperature, relative humidity, and velocity of air), and the type of solvent or nonsolvent used in the coating solution. Asymmetric-type coatings can be used to facilitate osmotic delivery of drugs with low solubilities since high water fluxes can be achieved. These coatings allow us to control the release kinetics without altering the coating material or significantly varying the coating thickness.

Currently, considerable research efforts have been directed toward developing protein drug delivery systems due to discovery of numerous protein and peptide therapeutics. The delivery of protein drugs is usually limited to parenteral administration and frequent injections are required due to their short half-lives in the blood. In this regard, development of oral delivery systems is necessary for patient compliance and convenience. The challenge in the design of the oral delivery systems is that they should protect the incorporated drugs from chemical and enzymatic degradation until the drug reaches the delivery site. The protein drug should not be influenced by $\mathrm{pH}$ or bacteria and enzymes along the gastrointestinal (GI) tract and should be delivered at the desired site with a desired efficiency. To achieve sitespecific delivery for protein- and peptide-based drugs, one of the strategies that has often been investigated is to coat the drug core with polymers that can respond to the stimuli of local environments such as $\mathrm{pH}$ and enzymes. For water-soluble protein drugs, such as insulin, an additional protective coating is usually required to isolate the drug from the surrounding water. Composite tablet coating materials which combine the enzymatic susceptibility and protective properties of polymers can be another solution for this problem. A systematic comparison study among various polymer combinations is required to select the appropriate coating materials for specific drugs. Not only the selection of the coating material but also the manufacturing technique for the preparation of tablet coatings plays a critical role and still remains one of the most challenging subjects in the controlled drug delivery area. Proteins are very sensitive to conditions that can occur during the coating process. Mechanical stresses during the preparation, exposure to a hydrophobic organic solvent, intermediate moisture level during hydration, and interaction between protein and polymer can easily inactivate the protein-based drug. Therefore, more research focused on both optimization of coating materials and manufacturing methods for encapsulating the protein and peptide drugs is necessary. 


\section{REFERENCES}

1. Langer, R. S., and Peppas, N. A. (1981), Present and future applications of biomaterials in controlled drug delivery systems, Biomaterials, 2, 201-214.

2. Ho, W. S. W., and Sirkar, K. K. (1992), Membrane Handbook, Van Nostrand Reinhold, New York, pp. 915-935.

3. Liu, L., Ku, J., Khang, G., Lee, B., Rhee, J. M., and Lee, H. B. (2000), Nifedipine controlled delivery by sandwiched osmotic tablet system. J. Controlled Release, 68 , 145-156.

4. Liu, L., Khang, G., Rhee, J. M., and Lee, H. B. (2000), Monolithic osmotic tablet system for nifedipine delivery, J. Controlled Release, 67, 309-322.

5. Narisawa, S., Nagata, M., Ito, T., Yoshino, H., Hirakawa, Y., and Noda, K. (1995), Drug release behavior in gastrointestinal tract of beagle dogs from multiple unit type ratecontrolled or time-controlled release preparations coated with insoluble polymer-based film, J. Controlled Release, 33, 253-260.

6. Moussa, I. S., and Cartilier, L. H. (1997), Evaluation of cross-linked amylose press-coated tablets for sustained drug delivery, Int. J. Pharm., 149, 139-149.

7. Khan, M. Z. I., Prebeg, E., and Kurjakovic, N. (1999), A pH-dependent colon targeted oral drug delivery system using methacrylic acid copolymers: I. Manipulation of drug release using Eudragit ${ }^{\circledR}$ L100-55 and Eudragit ${ }^{\circledR}$ S100 combinations, J. Controlled Release, $\underline{58,215-222 .}$

8. Krögel, I., and Bodmeier, R. (1999), Floating or pulsatile drug delivery systems based on coated effervescent cores, Int. J. Pharm., 187, 175-184.

9. Macleod, G. S., Fell, J. T., and Collett, J. H. (1999), An in vitro investigation into the potential for bimodal drug release from pectin/chitosan/HPMC-coated tablets, Int. J. Pharm., 188, 11-18.

10. Thoma, K., and Bechtold, K. (1999), Influence of aqueous coatings on the stability of enteric coated pellets and tablets, Eur. J. Pharm. Biopharm., 47, 39-50.

11. Fukui, E., Uemura, K., and Kobayashi, M. (2000), Studies on applicability of press-coated tablets using hydroxypropylcellulose (HPC) in the outer shell for timed-release preparations, J. Controlled Release, 68, 215-223.

12. Crotts, G., Sheth, A., Twist, J., and Ghebre-Sellassie, I. (2001), Development of an enteric coating formulation and process for tablets primarily composed of a highly watersoluble, organic acid. Eur. J. Pharm. Biopharm., 51, 71-76.

13. Ofori-Kwakye, K., and Fell, J. T. (2003), Biphasic drug release from film-coated tablets, Int. J. Pharm., 250, 431-440.

14. Goto, T., Tanida, O., Yoshinaga, T., Sato, S., Ball, D. J., Wilding, I. R., Kobayashi, E., and Fujimura, A. (2004), Pharmaceutical design of a novel colon-targeted delivery system using two-layer-coated tablets of three different pharmaceutical formulations, supported by clinical evidence in humans, J. Controlled Release, 97, 31-42.

15. Sundy, E., and Danckwerts, M. P. (2004), A novel compression-coated doughnut-shaped tablet design for zero-order sustained release, Eur. J. Pharm. Sci., 22, 477-485.

16. Tarvainen, M., Peltonen, S., Mikkonen, H., Elovaara, M., Tuunainen, M., Paronen, P., Ketolainen, J., and Sutinen, R. (2004), Aqueous starch acetate dispersion as a novel coating material for controlled release products, J. Controlled Release, 96, 179-191.

17. Thombre, A. G., Appel, L. E., Chidlaw, M. B., Daugherity, P. D., Dumont, F., Evans, L. A. F., and Sutton, S. C. (2004), Osmotic drug delivery using swellable-core technology, J. Controlled Release, 94, 75-89. 
18. Kim, I. H., Park, J. H., Cheong, I. W., and Kim, J. H. (2003), Swelling and drug release behavior of tablets coated with aqueous hydroxypropyl methylcellulose phthalate (HPMCP) nanoparticles, J. Controlled Release, 89, 225-233.

19. Okimoto, K., Rajewski, R. A., and Stella, J. V. (1999), Release of testosterone from an osmotic pump tablet utilizing (SBE) $7 \mathrm{~m}-\beta$-cyclodextrin as both a solubilizing and an osmotic pump agent, J. Controlled Release, 58, 29-38.

20. Khan, M. A., Sastry, S. V., Vaithiyalingam, S. R., Agarwal, V., Nazzal, S., and Reddy, I. K. (2000), Captopril gastrointestinal therapeutic system coated with cellulose acetate pseudolatex: Evaluation of main effects of several formulation variables, Int. J. Pharm., 193, 147-156.

21. Lu, E-X., Jiang, Z-Q., Zhang, Q-Z., and Jiang, X-G. (2003), A water-insoluble drug monolithic osmotic tablet system utilizing gum arabic as an osmotic, suspending and expanding agent, J. Controlled Release, 92, 375-382.

22. Zhang, Y., Zhang, Z., andw. F. (2003), A novel pulsed-release system based on swelling and osmotic pumping $\mathrm{m}$ 三

8 23. Liu, L., and Che, B. (in press), Preparation of monolith coating the indented core tablet, Eur. J. Pharm. Biopharm.

24. Zentner, G. M., Rork, G. S., and Himmelstein, K. J. (1985), The controlled-porosity osmotic pump, J. Controlled Release, 1, 269-282.

25. Baker, R. W., and Brooke, J. W. (1987), Pharmaceutical drug delivery system, U.S. Patent 4,687,660.

26. Theeuwes, F., and Ayer, A. D. (1978), Osmotic device having composite walls, U.S. Patent 4,077,407.

27. Theeuwes, F. (1978), Microporous-semipermeable laminated osmotic system, U.S. Patent $4,256,108$.

28. Cortese, R., and Theeuwes, F. (1982), Osmotic device with hydrogel driving member, U.S. Patent 4,327,725.

29. Swanson, D. R., Burday, B. L., Wong, P. S. L., and Theeuwes, F. (1987), Nifedipine gastrointestinal therapeutic system, Am. J. Med., 83, 3-10.

30. Herbig, S. M., Cardinal, J. R., Korsmeyer, R. W., and Smith, K. L. (1995), Asymmetric membrane tablet coatings for osmotic drug delivery, J. Controlled Release, 35, 127136.

31. Cardinal, J. R., Herbig, S. M., Korsmeyer, R. W., Lo, J., Smith, K. L., and Thombre, A. G. (1997), Use of asymmetric membranes in delivery devices, U.S. Patent $5,612,059$.

32. Cardinal, J. R., Herbig, S. M., Korsmeyer, R. W., Lo, J., Smith, K. L., and Thombre, A. G. (1997), Asymmetric membranes in delivery devices, U.S. Patent 5,698,220.

33. Wang, D-M., Lin, F-C., Chen, L-Y., and Lai, J-Y. (1998), Application of asymmetric TPX membranes to transdermal delivery of nitroglycerin, J. Controlled Release, 50, 187-195.

34. Thombre, A. G., Cardinal, J. R., DeNoto, A. R., Herbig, S. M., and Smith, K. L. (1999), Asymmetric-membrane capsules for osmotic drug delivery. Part I: Development of a manufacturing process, J. Controlled Release, 57, 55-64.

35. Thombre, A. G., Cardinal, J. R., DeNoto, A. R., and Gibbes, D. C. (1999), Asymmetric membrane capsules for osmotic drug delivery. Part II: In vitro and in vivo drug release performance, J. Controlled Release, 57, 65-73.

36. Thombre, A. G., DeNoto, A. R., and Gibbes, D. C. (1999), Delivery of glipizide from asymmetric-membrane capsules using encapsulated excipients, J. Controlled Release, 60,333-341. 
37. Lin, Y-K., and Ho, H-O. (2003), Investigations on the drug releasing mechanism from an asymmetric-membrane-coated capsule with an in situ formed delivery orifice, J. Controlled Release, 89, 57-69.

38. Meier, M. M., Kanis, L. A., and Soldi, V. (2004), Characterization and drug-permeation profiles of microporous and dense cellulose acetate membranes: Influence of plasticizer and pore forming agent, Int. J. Pharm., 278, 99-110.

39. Prabakaran, D., Singh, P., Jaganathan, K. S., and Vyas, S. P. (2004), Osmotically regulated asymmetric capsular systems for simultaneous sustained delivery of anti-tubercular drugs, J. Controlled Release, 95, 239-248.

40. Wang, C-Y., Ho, H-O., Lin, L-H., Lin, Y-K., and Ming-Thau Sheu, M-T. (2005), Asymmetric membrane capsules for delivery of poorly water-soluble drugs by osmotic effects, Int. J. Pharm., 297, 89-97.

41. Altinkaya, S. A., and Yenal, H. (2006), In vitro drug release rates from asymmetricmembrane tablet coatings: Prediction of phase-inversion dynamics, Biochem. Eng. J., 28, 131-139.

9 42. Wang, G-M., Chen, C-H., Ho, H-O., Wang, S-S. and Sheu, M-T. (in press), Novel design of osmotic chitosan capsules characterized by $\bar{\equiv}$ nmetric membrane structure for in situ formation of delivery orifice, Int. J. Pharm.

43. Altinkaya, S. A., and Ozbas, B. (2004), Modeling of asymmetric-membrane formation by dry-casting method, J. Membr. Sci., 230, 71-89.

44. Mathiowitz, M. (1999), Encyclopedia of Controlled Drug Delivery, Wiley, New York, pp. 302-303.

45. Sandadi, S., PAndey, P., and Turton, R. (2004), In situ, near real-time acquisition of particle motion in rotating pan coating equipment using imaging techniques, Chem. Eng. Sci., 59, 5807-5817.

46. Prater, D., Wilde, J., and Meakin, B. (1980), A model system for the production of aqueous tablet film coating for laboratory evaluation, J. Pharm. Pharmacol., 32(Suppl.), 90.

47. Leaver, T., Shannon, H., and Rowe, R. (1985), A photometric analysis of tablet movement in a side-vented perforated drum (Accela-Cota), J. Pharm. Pharmacol., 37, 17-21.

48. Nakagawa, M., Altobelli, S., Caprihan, A., Fukushima, E., and Jeong, E. (1993), Noninvasive measurements of granular flows by magnetic resonance imaging, Exper. Fluids, 16, 54-60.

49. Parker, D., Broadbent, C., Fowles, P., Hawkesworth, M., and McNeil, P. (1993), Positron emission particle tracking-A technique for studying flow within engineering equipment, Nucl. Instrum. Methods Phys. Res. A, 326, 592-607.

50. Parker, D., Dijkstra, A., Martin, T., and Seville, J. (1997), Positron emission particle tracking studies of spherical particle motion in rotating drums, Chem. Eng. Sci., 52, 2011-2022.

51. Wilson, K., and Crossman, E. (1997), The influence of tablet shape and pan speed on intra-tablet film coating uniformity, Drug Dev. Ind. Pharm., 23, 1239-1243.

52. Yamane, K., Sato, T., Tanaka, T., and Tsuji, Y. (1995), Computer simulation of tablet motion in coating drum, Pharm. Res., 12, 1264-1268.

53. Yamane, K., Nakagawa, M., Altobelli, S., Tanaka, T., and Tsuji, Y. (1998), Steady particulate flows in a horizontal rotating cylinder, Phys. Fluids, 10, 1419-1427.

54. Denis, C., Hemati, M., Chulia, D., Lanne, J., Buisson, B., Daste, G., and Elbaz, F. (2003), A model of surface renewal with application to the coating of pharmaceutical tablets in rotary drums, Powder Technol., 130, 174-180. 
55. Pandey, P., Song, Y., Kayihan, F., and Turton, R. (2006), Simulation of particle movement in a pan coating device using discrete element modeling and its comparison with videoimaging experiments, Powder Technol., 161, 79-88.

56. Rege, B. D., Gawel, J., and Kou, J. H. (2002), Identification of critical process variables for coating actives onto tablets via statistically designed experiments, Int. J. Pharm., 237, 87-94.

57. Turton, R., and Cheng, X. X. (2005), The scale-up of spray coating processes for granular solids and tablets, Powder Technol., 150, 78-85.

58. Xu, M., and Turton, R. (1997), A new data processing technique for noisy signals: Application to measuring particle circulation times in a draft tube equipped fluidized bed, Powder Technol., 92, 111-117.

59. Sherony, D. F. (1981), A model of surface renewal with application to fluid bed coating of particles, Chem. Eng. Sci., 36, 845-848.

60. Wnukowski, P., and Setterwall, F. (1989), The coating of particles in a fluidized bed (residence time distribution in a system of two coupled perfect mixers), Chem. Eng. Sci., 44, 493-505.

61. Choi, M. S., and Meisen, A. (1997), Sulfur coating of urea in shallow spouted beds, Chem. Eng. Sci., 52, 1073-1086.

62. Maronga, J., and Wnukowski, P. (1997), Modeling of the three-domain fluidized bed particulate coating process, Chem. Eng. Sci., 52, 2915-2925.

63. Nakamura, H., Abe, E., and Yamada, N. (1998), Coating mass distributions of seed particles in a tumbling fluidized bed coater. Part II. A Monte Carlo simulation of particle coating, Powder Technol., 99, 140-146.

64. Cheng, X. X., and Turton, R. (2000), The prediction of variability occurring in fluidized bed coating equipment. II: The role of nonuniform $\equiv$ ticle coverage as particle pass through the spray zone, Pharm. Dev. Technol., 5, 32

10 65. KuShaari_K Pandey, P., Song, Y., and Turton, R. (in press), Monte Carlo simulations to determir $\bar{\equiv}$ ating uniformity in a Wurster fluidized bed coating process, Powder Technol.

66. Waterman, K. C., and Fergione, M. B. (2003), Press-coating of immediate release powders onto coated controlled release tablets with adhesives, J. Controlled Release, 89, 387-395.

67. Leong, K. C., Lu, G. Q., and Rudolph, V. (1999), A comparative study of the fluidized-bed coating of cylindrical metal surfaces with various thermoplastic polymer powders, J. Mater. Proc. Technol., 89/90, 354-360.

68. Wulf, M., Uhlmann, P., Michel, S., and Grundke, K. (2000), Surface tension studies of levelling additives in powder coatings, Prog. Org. Coat., 38, 59-66.

69. Belder, E. G., Rutten, H. J. J., and Perera, D. Y. (2001), Cure characterization of powder coatings, Prog. Org. Coat., 42, 142-149.

70. Pfeffer, R., Dave, R. N., Wie, D., and Ramlakhan, M. (2001), Synthesis of engineered particulates with tailored properties using dry particle coating, Powder Technol., 117, 40-67.

71. McLaren, D. D., and Hollenbeck, R. G. (1987), A high performance liquid chromatographic method for the determination of the amount of hydroxypropyl methylcellulose applied to tablets during an aqueous film coating operation, Drug Dev. Ind. Pharm., 13, 2179-2197.

72. Mouget, Y., Gosselin, P., Tourigny, M, and B'echard, S. (2003), Three-dimensional analyses of tablet content and film coating uniformity by laser-induced breakdown spectroscopy (LIBS), Am. Lab., 35, 20-22. 
73. St-Onge, L., Kwong, E., Sabsabi, M., and Vadas, E. B. (2002), Quantitative analysis of pharmaceutical products by laser-induced breakdown spectroscopy, Spectrochim. Acta, Part B, 57, 1131-1140.

74. Kirsch, J. D., and Drennen, J. K. (1995), Determination of film-coated tablet parameters by near-infrared spectroscopy. J. Pharm. Biomed. Anal., 13, 1273-1281.

75. Kirsch, J. D., and Drennen, J. K. (1996), Near-infrared spectroscopic monitoring of the film coating process, Pharm. Res., 13, 234-237.

76. Anderson, M., Josefson, M., Langkilde, F., and Wahlund, K.-G. (1999), Monitoring of a film coating process for tablets using near infrared reflectance spectrometry, J. Pharm. Biomed. Anal., 20, 27-37.

77. Romero-Torres, S., Pérez-Ramos, J. D., Morris, K. R., and Grant, E. R. (2006), Raman spectroscopy for tablet coating thickness quantification and coating characterization in the presence of strong fluorescent interference, J. Pharma. Biomed. Anal., 41, 811-819.

78. Romero-Torres, S., Pérez-Ramos, J. D., Morris, K. R., and Grant, E. R. (2005), Raman spectroscopic measurement of tablet-to-tablet coating variability, J. Pharm. Biomed. Anal., 38, 270-274.

79. Ruotsalainen, M., Heinämäki, J., Guo, H., Laitinen, N., and Yliruusi, J. (2003), A novel technique for imaging film coating defects in the film-core interface and surface of coated tablets, Eur. J. Pharm. Biopharm., 56, 381-388.

80. Podczeck, F. (1998), Measurement of surface roughness of tablets made from polyethylene glycol powders of various molecular weight, Pharm. Pharmacol. Commun., 4, 179-182.

81. Riippi, M., Antikainen, O., Niskanen, T., and Yliruusi, J. (1998), The effect of compression force on surface structure, crushing strength, friability, and disintegration time of erythromycin acistrate tablets, Eur. J. Pharm. Biopharm., 46, 339-345.

82. Newton, M., Petersson, J., Podczeck, F., Clarke, A., and Booth, S. (2001), The influence of formulation variables on the properties of pellets containing a self-emulsifying mixture, J. Pharm. Sci., 90, 987-995.

83. Seitavuopio, P., Rantanen, J., and Yliruusi, J. (2003), Tablet surface characterisation by various imaging techniques, Int. J. Pharm., 254, 281-286.

84. Seitavuopio, P., Rantanen, J., and Yliruusi, J. (2005), Use of roughness maps in visualisation of surfaces, Eur. J. Pharm. Biopharm., 59, 351-358.

85. van de Witte, P., Dijkstra, P. J., Van den Berg, J. W. A., and Feijen, J. (1996), Phase separation processes in polymer solutions in relation to membrane formation, J. Membr. Sci., $117,1-31$.

86. Han, M., and Bhattacharyya, D. (1995), Changes in morphology and transport characteristics of polysulfone membranes prepared by different demixing conditions, J. Membr. Sci., 98, 191-200.

87. Park, H. C., Kim, Y. P., Kim, H. Y., and Kang, Y. S. (1999), Membrane formation by water vapor induced phase inversion, J. Membr. Sci., 156, 169-178.

88. Tobiska, S., and Kleinebudde, P. (2001), A simple method for evaluating the mixing efficiency of a new type of pan coater, Int. J. Pharm., 224, 141-149.

89. Plumb, A. P., Rowe, R. C., York, P., and Doherty, C. (2002), The effect of experimental design on the modeling of a tablet coating formulation using artificial neural networks, Eur. J. Pharm. Sci., 16, 281-288.

90. Rege, B. D., Gawel, J. and Kou, H. J. (2002), Identification of critical process variables for coating actives onto tablets via statistically designed experiments, Int. J. Pharm., 237, 87-94. 
11 91. Liu, L., and Che, B. (in press), Preparation of monolitt $\equiv$ coating the indented core tablet, Eur. J. Pharm. Biopharm.

92. Mueller, R., and Kleinebudde, P. (in press), Influence of scale-up on the abrasion of $\equiv$ tablets in a pan coater, Eur. J. Pharm. Biopharm.

93. Wang, G-M., Chen, C-H., Ho, H-O., Wang, S-S., and Sheu, M-T. (press), Novel design of osmotic chitosan capsules characterized by asymmetric membrane structure for in situ formation of delivery orifice, Int. J. Pharm.

94. Hussain, A. S., Shivanand, P., and Johnson, R. D. (1994), Application of neural computing in pharmaceutical product development: Computer aided formulation design, Drug Dev. 三

95 Kesavan, J. G., and Peck, G. E. (1995), Pharmaceutical formulation using neural net三orks. Proc.14th Pharm. Technol. Conf. (Barcelona), 2, 413-431.

96. Colbourn, E. A., and Rowe, R. C. (1996), Modeling and optimization of a tablet $\equiv$ formulation using neural networks and genetic algorithms, Pharm. Technol. Eur., 8, V7.

97. Bourquin, J., Schmidli, H., van Hoogevest, P., and Leuenberger, H. (1997), Basic concepts f artificial neural networks (ANN) modeling in the application to pharmaceutical $\equiv$ E evelopment, Pharm. Dev. Technol., 2, 95-109.

98. Bourquin, J., Schmidli, H., van Hoogevest, P., and Leuenberger, H. (1997b), Application $f$ artificial neural networks (ANN) in the development of solid dosage forms, Pharm. 鬲 Jev. Technol., 2,111-121.

99. Ebube, N. K., McCall, T., Chen, Y., and Meyer, M. C. (1997), Relating formulation variables to in vitro dissolution using an artificial neural network, Pharm. Dev. Technol., 2, 225-232.

100. Bourquin, J., Schmidli, H., van Hoogevest, P., and Leuenberger, H. (1998), Comparison of artificial neural networks (ANN) with classical modeling techniques using different experimental designs and data from a galenical study on a solid dosage form, Eur. J. Pharm. Sci., 6, 287-300.

101. Bourquin, J., Schmidli, H., van Hoogevest, P., and Leuenberger, H. (1998), Advantages of artificial neural networks (ANNs) as alternative modeling technique for data sets

$\equiv$ showing non-linear relationships using data from a galenical study on a solid dosage 三 form, Eur. J. Pharm. Sci., 7, 5-16.

102. Bourquin, J., Schmidli, H., van Hoogevest, P., and Leuenberger, H. (1998), Pitfalls of artificial neural networks (ANN) modeling technique for data sets containing outlier $\equiv$ measurements using a study on mixture properties of a direct compressed dosage form, $\equiv$ Eur. J. Pharm. Sci., 7, 17-28.

103. Chen, Y., McCall, T. W., Baichwal, A. R., and Meyer, M. C. (1999), The application of an artificial neural network and pharmacokinetic simulations in the design of controlled$\equiv$ 吾年ease dosage forms, J. Controlled Release, 59, 33-41.

104. Plumb, A. P., Rowe, R. C., York, P., and Doherty, C. (2002), The effect of experimental $\equiv$ lesign on the modeling of a tablet coating formulation using artificial neural networks, E Eur. J. Pharm. Sci., 16, 281-288.

105. Plumb, A. P., Rowe, R. C., York, P., and Doherty, C. (2003), Effect of varying optimization parameters on optimization by guided evolutionary simulated annealing

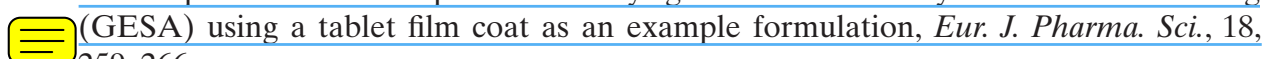
259-266.

106. Takayama, K., Fujikawa, M., Obata, Y., and Morishita, M. (2003), Neural network based optimization of drug formulations, Adv. Drug Deliv. Rev., 55, 1217-1231. 
107 Montgomery, D. C. (1997), Design and Analysis of Experiments, 4th ed., Wiley, New York,

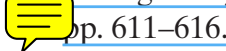

108. Lai, J.-Y., Lin, F.-C., Wang, C.-C., and Wang, D.-M. (1996), Effect of nonsolvent additives $\equiv$ on the porosity and morphology of asymmetric TPX membranes, J. Membr. Sci., 118, 49-61.

109. Broadhead, K. W., and Tresco, P. A. (1998), Effects of fabrication conditions on the structure and function of membranes formed from poly(acrylonitrile-vinylchloride),

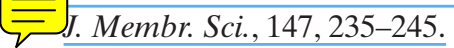

110. Won, J., Park, H. C., Kim, U. Y., Kang, S., Yoo, S. H., and Jho, J. Y. (1999), The effect of $\equiv$ dope solution characteristics on the membrane morphology and gas transport proper$\overline{\bar{\nu}}$ ties: PES/-BL/NMP system, J. Membr. Sci., 162, 247-255.

111. Young, T-H., Lin, D.-J., Gau, J.-J., Chuang, W.-Y., and Cheng, L.-P. (1999), Morphology of crystalline Nylon-610 membranes prepared by the immersion-precipitation process: $\equiv$ Competition between crystallization and liquid-liquid phase separation, Polymer, 40, $\overline{\bar{\nu}} 5011-5021$.

112. Chuang, W.-Y., Young, T.-H., Chiu, W.-Y., and Lin, C.-Y. (2000), The effect of polymeric $\equiv$ dditives on the structure and permeability of poly(vinyl alcohol) asymmetric$\overline{\bar{\nu}}$ membranes, Polymer, 41, 5633-5641.

113. Won, J., Lee, H. J., and Kang, Y. S. (2000), The effect of dope solution characteristics on $\equiv$ he membrane morphology and gas transport properties. Part 2: PES/BL system, Membr. Sci., 176, 11-19.

114. Fan, S.-C., Wang, Y.-C., Li, C.-L., Lee, K.-R., Liaw, D.-J., Huang, H.-P., and Lai, J.-Y. (2002), $\equiv$ Effect of coagulation media on membrane formation and vapor permeation performance of novel aromatic polyamide membrane, J. Membr. Sci., 204, 67-79.

115. Mohamed, N. A., and Al-Dossary, A. O. H. (2003), Structure-property relationships for novel wholly aromatic polyamide-hydrazides containing various proportions of paraphenylene and meta-phenylene units. Part III: Preparation and properties of semipermeable membranes for water desalination by reverse osmosis separation performance, $\overline{\bar{E}}$ Eur. Polym. J., 39, 1653-1667.

12 116. Pinnau, I., and Koros, W. (1991), Structures and gas separation property asymmetric $\equiv$ polysulfone membranes made by dry, wet, and dry/wet phase-inversion, J. Appl. Polym. $\overline{\bar{V}}_{\text {Sci., 43, 1491-1502. }}$

117. Sharpe, I. D., Ismail, A. F., and Shilton, S. J. (1999), A study of extrusion shear and forced $\equiv$ convection residence time in the spinning of polysulfone hollow fiber membranes for $\overline{\bar{E}}$ gas separation, Sep. Purif. Technol., 17, 101-109.

118. Ismail, A. F., Ng, B. C., and Abdul Rahman, W. A. W. (2003), Effects of shear rate and $\equiv$ Orced convection residence time on asymmetric polysulfone membranes structure and gas separation performance, Sep. Purif. Technol., 33, 255-272.

119 Matsuyama, H., Teramoto, M., and Uesaka, T. (1997), Membrane formation and struc$\equiv$ ure development by dry cast process, J. Membr. Sci., 135, 271-288.

120. Jansen, J. C., Macchione, M., and Drioli, E. (2005), High flux asymmetric gas separation membranes of modified poly(ether ether ketone) prepared by the dry phase inversion $\overline{\overline{\bar{\tau}}}$ echnique, J. Membr. Sci., 255, 167-180.

121. Jansen, J. C., Buonomenna, M. G., Figoli, A., and Drioli, E. (2006), Asymmetric memranes of modified poly(ether ether ketone) with an ultra-thin skin for gas and vapour separations, J. Membr. Sci., 272, 188-197.

122. Kleinbaum, D. G., Kupper, L. L., and Muller, K. E., (1987), Applied Regression Analysis and Other Multivariable Methods, 2nd ed., Duxbury, Belmont, pp. 658-659. 


\section{APPENDIX}

The in vitro release profiles of the model drug theophylline are shown below in Figures A1 through A10.

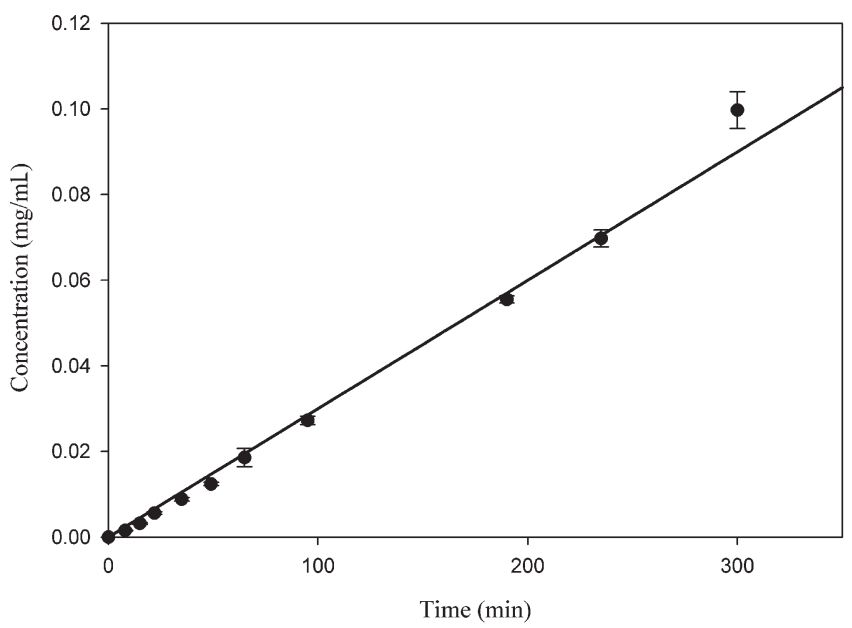

FIGURE A1 Release of theohylline from tablet coatings made with 5\% CA dissolved in $90 \%$ acetone and $5 \%$ water.

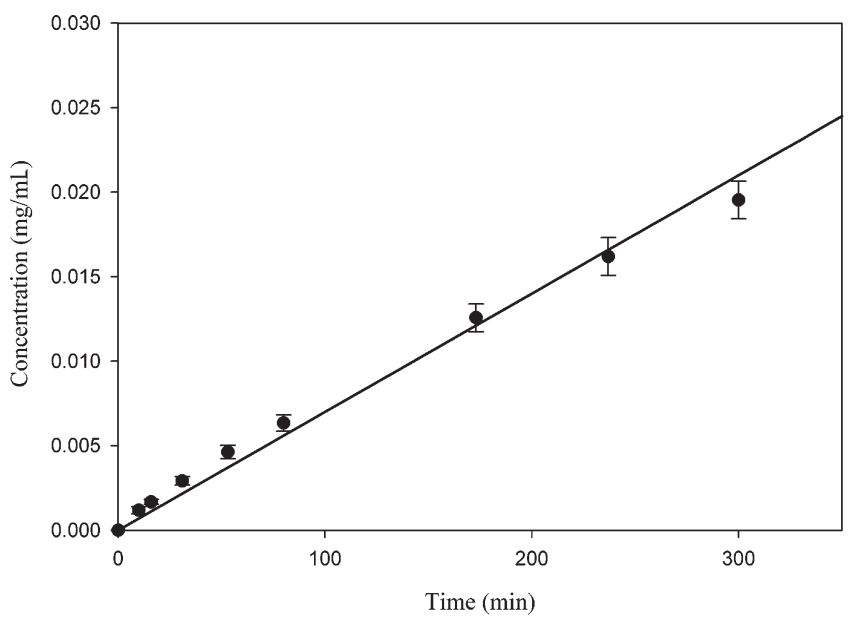

FIGURE A2 Release of theohylline from tablet coatings made with 10\% CA dissolved in $85 \%$ acetone and $5 \%$ water. 


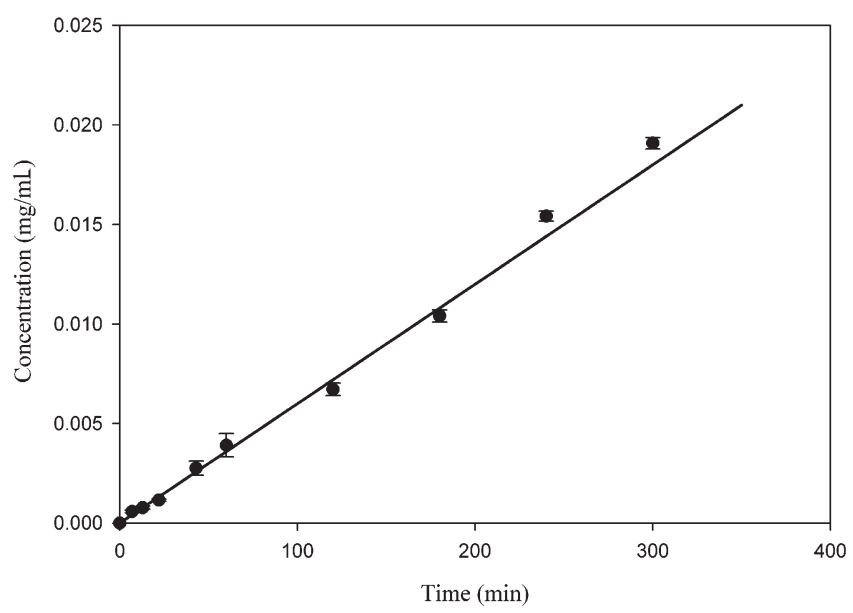

FIGURE A3 Release of theohylline from tablet coatings made with 15\% CA dissolved in $80 \%$ acetone and $5 \%$ water.

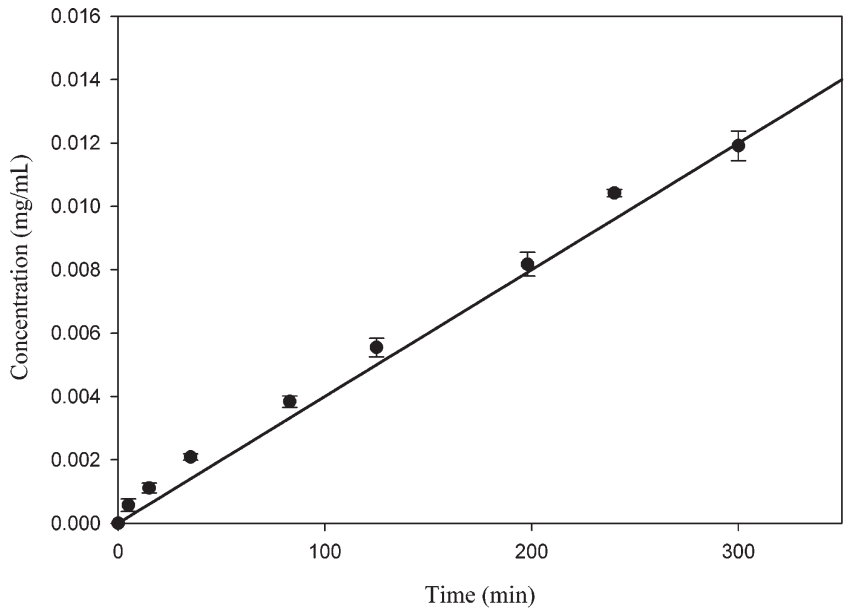

FIGURE A4 Release of theohylline from tablet coatings made with 5\% CA dissolved in $85 \%$ acetone and $10 \%$ water. 


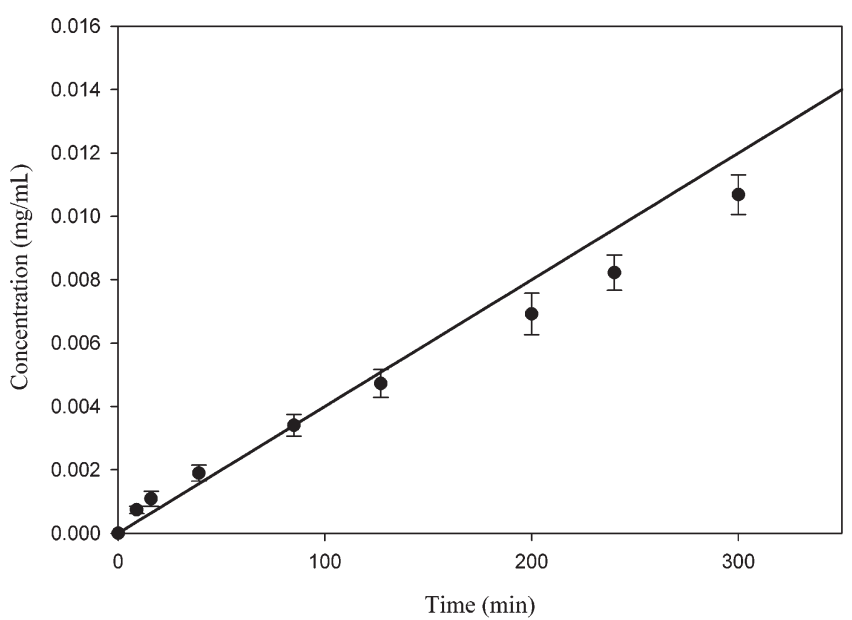

FIGURE A5 Release of theohylline from tablet coatings made with 10\% CA dissolved in $80 \%$ acetone and $10 \%$ water.

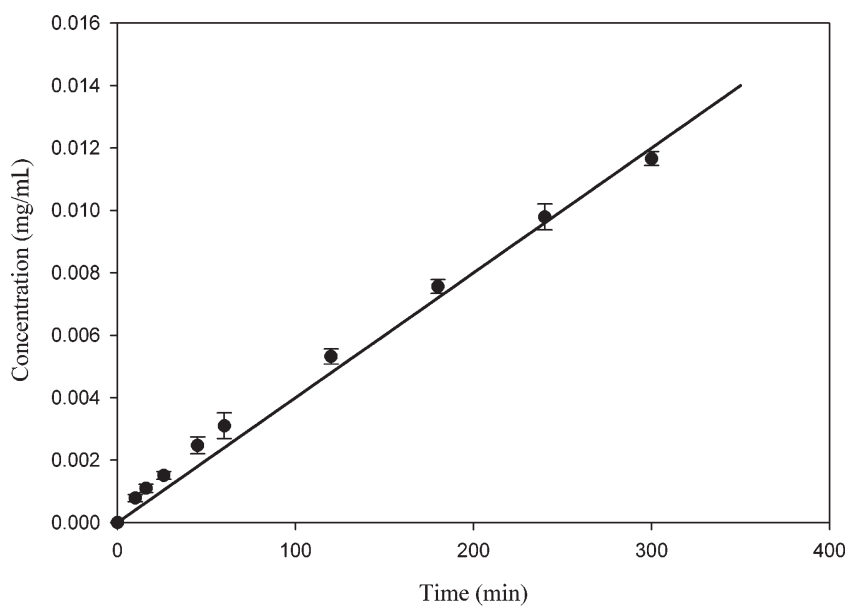

FIGURE A6 Release of theohylline from tablet coatings made with 15\% CA dissolved in $75 \%$ acetone and $10 \%$ water. 


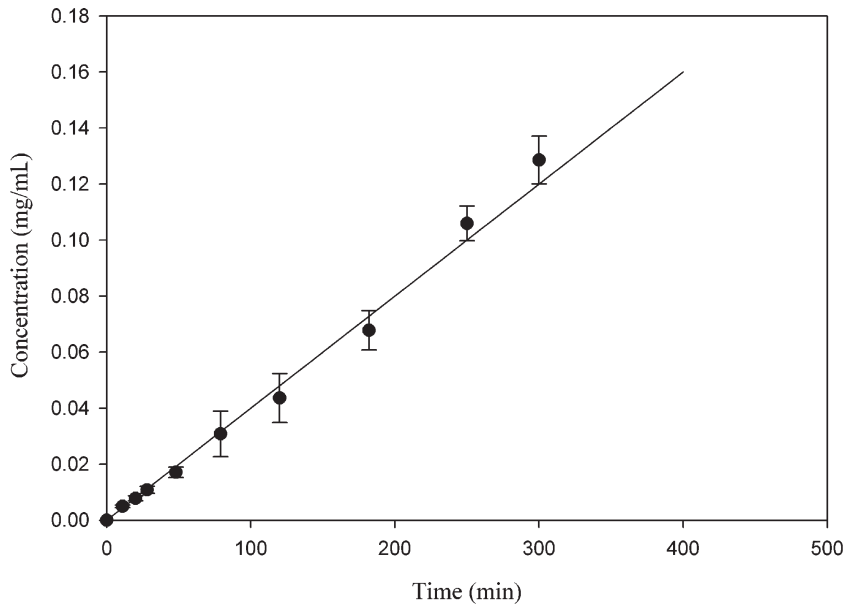

FIGURE A7 Release of theohylline from tablet coatings made with 5\% CA dissolved in $80 \%$ acetone and $15 \%$ water.

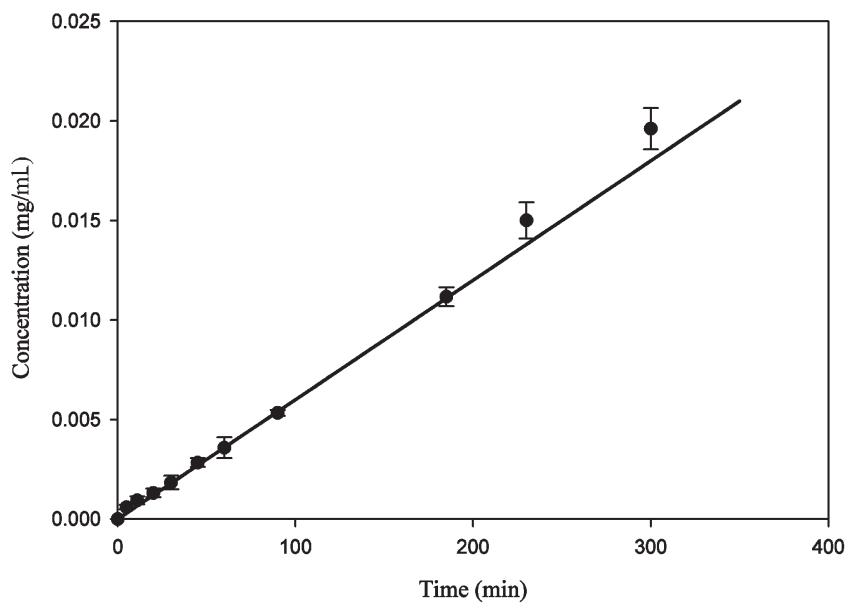

FIGURE A8 Release of theohylline from tablet coatings made with 10\% CA dissolved in $75 \%$ acetone and $15 \%$ water. 


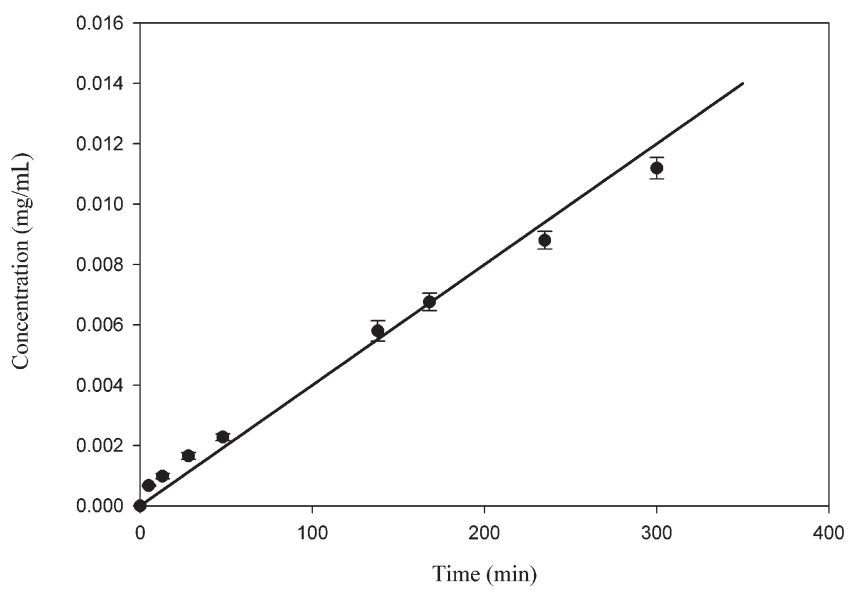

FIGURE A9 Release of theohylline from tablet coatings made with 15\% CA dissolved in $70 \%$ acetone and $15 \%$ water.

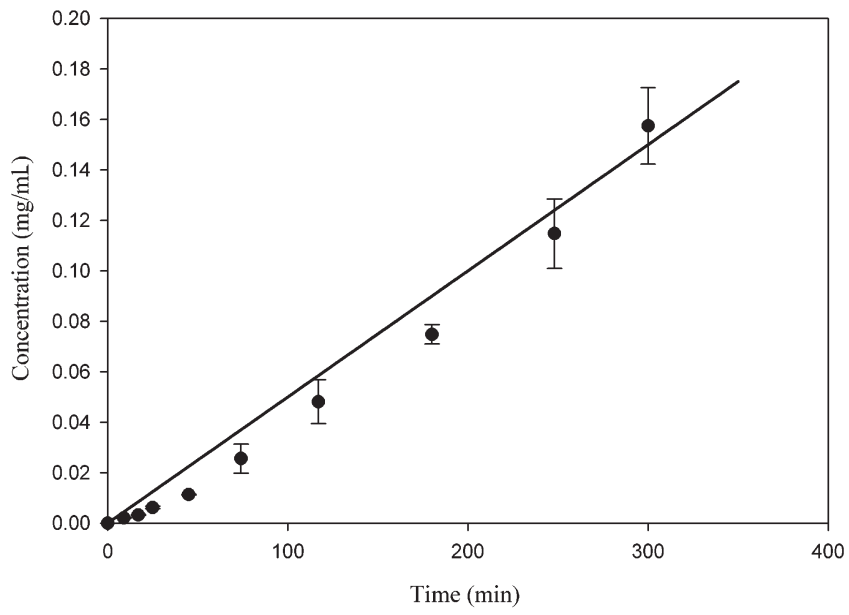

FIGURE A10 Release of theohylline from tablet coatings made with $12.5 \%$ CA dissolved in $77.5 \%$ acetone and $10 \%$ water. 


\section{Author Queries Form}

Dear Author,

During the preparation of your manuscript for publication, the questions listed below have arisen. Please attend to these matters and return this form with your proof.

Many thanks for your assitstance.

\begin{tabular}{|c|c|c|}
\hline $\begin{array}{l}\text { Query } \\
\text { References }\end{array}$ & Query & Remarks \\
\hline 1 & $\begin{array}{l}\text { Au: Check that Appendix has been added; if not, delete } \\
\text { here }\end{array}$ & \\
\hline 2 & $\mathrm{Au}:$ "and" OK? & \\
\hline 3 & $\begin{array}{l}\text { Au: Check title of Appendix here \& in chapter contents. } \\
\text { If there is only one no need to have the "A" }\end{array}$ & \\
\hline 4 & Au: As meant? & \\
\hline 5 & Au: Please check sense & \\
\hline 6 & Au: As meant? & \\
\hline 7 & $\begin{array}{l}\text { Au: Please provide Appendix and place before Refs. } \\
\text { Check thats Figs A1-A10 are cited there. }\end{array}$ & \\
\hline 8 & Au: Any update? & \\
\hline 9 & Au: Update? & \\
\hline 10 & Au: Update? & \\
\hline 11 & $\mathrm{Au}:$ Update? & \\
\hline 12 & Au: As meant? & $\equiv$ \\
\hline
\end{tabular}

